\title{
Steel fibre reinforced concrete for elements failing in bending and in shear
}

\author{
Joaquim A. O. Barros ${ }^{\star 1 a}$, Lúcio A. P. Lourenço ${ }^{1 b}$, Fatemeh Soltanzadeh ${ }^{1 \mathrm{c}}$, and Mahsa \\ Taheri $^{1 \mathrm{~d}}$
}

\author{
${ }^{1}$ ISISE, Dept. of Civil Engineering, Univ. of Minho, Azurém, 4800-058 Guimarães, Portugal \\ *a Full Professor, Corresponding author, E-mail: barros@ civil.uminho.pt

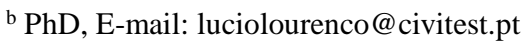 \\ c PhD Candidate, E-mail: f.soltanzadeh@ civil.uminho.pt \\ d PhD Candidate, E-mail: taheri@ civil.uminho.pt
}

\begin{abstract}
Discrete steel fibres can increase significantly the bending and the shear resistance of concrete structural elements when Steel Fibre Reinforced Concrete (SFRC) is designed in such a way that fibre reinforcing mechanisms are optimized. To assess the fibre reinforcement effectiveness in shallow structural elements failing in bending and in shear, experimental and numerical research were performed. Uniaxial compression and bending tests were executed to derive the constitutive laws of the developed SFRC. Using a cross-section layered model and the material constitutive laws, the deformational behaviour of structural elements failing in bending was predicted from the moment-curvature relationship of the representative cross sections. To evaluate the influence of the percentage of fibres on the shear resistance of shallow structures, three point bending tests with shallow beams were performed. The applicability of the formulation proposed by RILEM TC 162-TDF for the prediction of the shear resistance of SFRC elements was evaluated. Inverse analysis was adopted to determine indirectly the values of the fracture mode I parameters of the developed SFRC. With these values, and using a softening diagram for modelling the crack shear softening behaviour, the response of the SFRC beams failing in shear was predicted.
\end{abstract}

Keywords: Shallow Structures; Fibre Reinforced Concrete; Moment-Curvature Relationship; Shear Reinforcement; Crack Shear Softening diagram; Material Nonlinear Analysis; FEM. 


\section{Introduction}

The precast concrete industry is frequently requested to produce reinforced concrete structural elements of high geometric complexity. These geometric conditions introduce difficulties on the placement of the reinforcement, which can increase significantly the production time and final price. The replacement of ordinary steel reinforcement by steel fibres can represent a great advance in this industry.

The use of discrete steel fibres as a reinforcement system for cement based materials is now a current practice for several applications, such as industrial floors, tunnel lining, prefabricated elements, and hydraulic structures (di Prisco et al. 2004). The resulting material is designated Steel Fibre Reinforced Concrete (SFRC). The post cracking residual strength can be much higher in SFRC than in the homologous (same compressive strength class) plain concrete (PC) due to fibre reinforcement mechanisms provided by fibres bridging the cracks (Barros et al. 2005). In consequence, SFRC allows high level of stress redistribution by providing a significant increase of load carrying capacity after crack initiation. Furthermore, the deformation capacity of a structure between the phases corresponding to crack initiation and its failure can increase considerably which contributes for the development of structures of larger safety. This is especially relevant in structures of redundant number of supports (Barros and Figueiras 1998; Barros et al. 2009). The level of the post cracking residual strength depends of several factors, such as: fibre geometric characteristics, fibre material properties, concrete properties, method of SFRC application.

When well conceived, fibre reinforcement can be replaced totally or partially with the conventional steel reinforcement for the flexural and shear resistance of concrete elements (Casanova 1995, Roshani 1996). The percentage of this replacement depends on the type of element, support and loading conditions and the postcracking resistance of FRC. Recently the FRC was classified as a tensile Strain-Softening (SS) FRC or a tensile Strain-Hardening (SH) FRC, depending on the evolution of the tensile stress after crack initiation (Naaman and Reinhard 2005). According to this classification, a SS-FRC is characterized by a post-cracking tensile stress that is lower than its tensile strength at crack initiation, while SH-FRC has a post-cracking tensile stress that is higher than its stress at crack initiation and a macro-crack with strain localization is formed at a tensile strain higher than $2 \%$. The typical feature of SH-FRC is the development of a diffuse crack pattern before the localization of the failure macro-crack (Pereira et al. 2010).

To contribute for this line of research, in the present work experimental and numerical research were carried out to assess the steel fibre reinforcement effectiveness for the shallow structural elements failing in bending and in 
shear (ACI 318 2008). A parametric study is carried out to evidence the effect of relevant characteristics of the post-cracking behaviour of SS- and SH-FRC in the moment-curvature and force-deflection responses of this type of structural elements. The performance of the analytical approach recommended by RILEM TC 162 TDF (2003) for the prediction of the fibre reinforcement contribution in terms of shear resistance of concrete beams is also assessed.

Modelling the behaviour of SFRC beams failing in shear under the framework of the material nonlinear finite element analysis is still a challenge due to the difficulty of simulating accurately the constitutive laws for the crack opening and crack sliding. To determine the fracture mode I parameters of the developed SFRC, used to define the diagram that simulates the crack opening initiation and propagation, an inverse analysis (Barros et al. 2005) was carried out with the experimental results obtained in three point notched beam bending tests executed according to the recommendations of RILEM TC 162 TDF for the characterization of SFRC (2003). For modelling the crack shear sliding behaviour, the first attempt was supported on the use of the shear retention factor (Sena-Cruz 2004) whose value progressively decreases with the increase of the crack opening. However, with this strategy the model was not able of predicting the occurred shear failure modes, and a too high load carrying capacity for the beams was predicted. To overcome this deficiency of the model, a shear softening diagram was used to simulate the fracture mode II, which was a strategy already proposed by other authors for plain concrete beams (Rots and de Borst 1987). With this strategy the maximum load of the tested beams was captured with acceptable accuracy, as well as the structural softening behaviour of the beams and the shear failure mode. Further information on the numerical simulation of material nonlinear behaviour of concrete structures is available elsewhere (de Borst 2002).

\section{Steel fibre reinforced concrete for reinforced concrete elements failing in bending}

\subsection{Introduction}

Due to the reinforcement mechanisms provided by fibres bridging the crack surfaces, steel fibres have been used to enhance both the flexural and shear strength of concrete elements. In flexure, the presence of fibres decreases the crack width and the average crack spacing (Vandewalle 2000, Chiaia et al. 2009) and increase the load carrying capacity at serviceability and ultimate limit states of structural members (Swamy and Al-Ta'an, 1981).

The simulation of the contribution of steel fibres for the behaviour of laminar structures (slabs, shallow beams 
or shells) of SFRC failing in bending is still a challenge, since several parameters influence this contribution, such as: geometrical characteristics and material properties of the fibres; concrete properties; method of SFRC application; geometry of the structure; loading conditions. Due to this fact, there are several approaches for modelling the fibres reinforcement contribution, but none of them has received a full acceptance of the scientific community, which does not contribute for a more extended use of this high performance material, even in applications where its use would result in technical and economic advantages.

The advantages associated to the addition of steel fibres to concrete mixes may be potentiated by using concrete with self-compacting requirements (Okamura 1997) resulting a Steel Fibre Reinforced Self-Compacting Concrete (SFRSCC). The option for a SFRC with self-compacting requisites in this experimental research aims of assuring a fibre distribution along the depth of the beams with higher homogeneity than in regular SFRC compositions, since vibration practice in the casting procedures promotes an increase of the fibre percentage from the top to the bottom of the element (Barros and Antunes 2013). Therefore, for the assessment of steel fibre reinforcement effectiveness for shallow structures failing in bending, SFRSCC was used.

\subsection{Experimental program}




\subsubsection{Test series}

The experimental program is composed of three series of shallow beams. Each one has a shear span $(a=450 \mathrm{~mm})$ almost equal to 3.5 times the effective depth of the beam cross section $(a / d \approx 3.5)$, a total length of $1600 \mathrm{~mm}$, a distance between supports of $1350 \mathrm{~mm}$ and a cross section area of $350 \times 150 \mathrm{~mm}^{2}$ (see Fig. 1). A different percentage of longitudinal reinforcement was adopted for each series of beams: $3 \phi 6(\rho=0.2), 3 \phi 8($ $\rho=0.36)$ and $3 \phi 10(\rho=0.56)$, having been attributed the designations of A, B and C for these series, respectively. In all tested beams, three steel bars of $6 \mathrm{~mm}$ diameter were applied in the top part of the cross section. Twelve beams were tested: six reinforced with steel fibres and the other six without steel fibres, used for comparison purposes. To keep the longitudinal bars in the aimed positions, one steel stirrup was positioned in the alignment of the supports and in the symmetry axis of the beam. The concrete cover thickness of these bars was assured by using spacers.

\subsubsection{Mix compositions}

The mix composition adopted for manufacturing the SFRSCC was optimized for a solid skeleton that includes $45 \mathrm{~kg}$ of the selected steel fibres per $\mathrm{m}^{3}$ of concrete. This mix composition was obtained applying a design method that takes into account the strong perturbation effect produced by steel fibres on the flowability of fresh concrete. In fact, steel fibres are stiff and do not easily accommodate to the dynamically changing shape of the bulk paste located between particles constituting the granular skeleton structure. Consequently, the design procedure and the optimization process followed to achieve self-compacting requirements are sensible to the fibre content, as well as the geometrical and material properties of the fibres (Pereira 2006; Barros et al. 2007). The characteristics of the SFRSCC mix composition are included in Table 1. The materials used were cement (C) CEM I 52.5R (rapid hardening and high strength cement, according to EN197-1:(2000), limestone filler MICRO 100 AB (LF), a superplasticizer (SP) with the trade name SIKA $3002 \mathrm{HE}$, water (W), four types of aggregates (fine river sand, FS; coarse river sand, CS; crushed calcareous 6-14 mm, CG_1; and crushed calcareous 14-20 mm, CG_2), and hooked ends steel fibres (SF) with a length ( $\left.l_{f}\right)$ of $60 \mathrm{~mm}$, a diameter $\left(d_{f}\right)$ of $0.75 \mathrm{~mm}$, an aspect ratio $\left(l_{f} / d_{f}\right)$ of 80 and a yield stress of $1100 \mathrm{MPa}$.

In the beams reinforced with conventional steel bars only, the self compacting concrete (SCC) mix was similar to the mix composition applied in the SFRC beams (see Table 1) apart the fact that the former ones does not 
include fibres. This is not the most appropriate procedure since the composition depends on the interferences introduced by the fibres. However, for this relatively small content of fibres $\left(45 \mathrm{~kg} / \mathrm{m}^{3}\right)$ it was assumed that the changes necessary to introduce in the mix composition due to the presence of fibres are not so significant that compromise the principal conclusions of the present work. For both compositions no visual signal of segregation was detected and the mixtures showed good homogeneity and cohesion. The total spread, $s$, and the time to reach a spread diameter of $500 \mathrm{~mm}, T_{f}$, measured with the slump cone in conjunction with $\mathrm{J}$ Ring, were measured, as well as the $H_{2} / H_{1}$ (blocking ratio) parameter of the L Box test (EFNARC 2002). The obtained results are indicated in Table 1 showing that the self-compacting requirements were assured.

\subsubsection{Test set up and monitoring system}

The beams were subject to four line loads distributed in the width of the beam's cross section (see Fig. 1). The force was registered by a load cell of $300 \mathrm{kN}$ maximum capacity while the deflections were measured from five LVDT's (Linear Voltage Differential Transducer), two of them of $25 \mathrm{~mm}$ measuring length $\left(l_{\text {meas }}\right)$ placed at the middle of the shear span, and the three others of $l_{\text {meas }}=50 \mathrm{~mm}$ located at the central part of the beam. To avoid the recordings of extraneous deflections like support settlements and deformability of the reaction frame, the LVDT's were supported on an aluminium bar fixed in the alignments of the supports of the beam, as represented in Fig. 1. The tests were carried out with servo-controlled equipment, imposing a deflection rate of $30 \mu \mathrm{m} / \mathrm{s}$ in the central LVDT for the test control purposes.

\subsubsection{Results and analysis}

A label $\mathrm{Li}_{-} \mathrm{j}_{-} \mathrm{k}$ was used to differentiate the tested beams, where: "L" can be replaced by $\mathrm{A}, \mathrm{B}$ or $\mathrm{C}$ to designate the series that the beam pertains; " $\mathrm{i}$ " identifies the number of the beam test in each series (two beams were tested per each series); "j” represents the diameter of the steel bars used as tensile longitudinal reinforcement; " $\mathrm{k}$ " represents the quantity of applied fibres (value in $\mathrm{kg}$ per $\mathrm{m}^{3}$ of concrete). For instance, A2_6_45 beam represents the second beam of "A" series that is reinforced with $6 \mathrm{~mm}$ diameter longitudinal steel bars and includes $45 \mathrm{~kg}$ of steel fibres per $\mathrm{m}^{3}$ of concrete. If " $\mathrm{i}$ " is omitted, the result represents the average value of the results of the beams of the corresponding series. The principal characteristics of each beam are indicated in Table 2. 
The relationship between the measured deflection at the midspan and the applied force of the tested beams is represented in Figs. 2, 3 and 4. Each curve corresponds to the average load values at each deflection level, obtained from the two beams of the corresponding series. From the analysis of these curves it is observed that after crack initiation the load carrying capacity of the SFRSCC beams is higher than the corresponding SCC ones. The difference of the load carrying capacity between these two types of beams increases from the crack initiation up to the maximum load of the SFRSCC beam. However, this difference decreases by increasing the percentage of the conventional reinforcement.

In terms of Serviceability Limit States (SLS) for deflection control, Eurocode 2 (2004) recommends that the maximum deflection of a structural member should not exceed a limit value in the range [L/250- $L / 500]$, depending on the type of structure, where $L$ is the span length of the member, in $\mathrm{mm}$. Assuming a limit value of $u=L / 400=3.4 m m\left(u_{S L S}\right)$ for the deflection, the corresponding force, $F_{S L S}$, was obtained (see Table 3, where $F^{F R C}$ is the force of the beam made by a fibrous composition and $F^{r e f}$ is the beam manufactured with the corresponding plain concrete). From the analysis of these values it can be verified that fibres increased $F_{S L S}$ from 1.29 up to 1.77 when the $F_{S L S}$ values of the SCC beams are taken for comparison purposes. This increase was as higher as lower was the reinforcement ratio of the longitudinal steel bars, $\rho$. This table also includes the values of the maximum forces supported by the tested beams $\left(F_{U L S}^{r e f}\right.$ and $F_{U L S}^{F R C}$ is the maximum force of the SCC and SFRSCC beam, respectively). From the analysis of the $F_{S L S}$ and $F_{U L S}$ values it can be concluded that $F_{S L S} / F_{U L S}$ ratio ranged from 0.66 to 0.95 in the beams without fibres, while in the beams reinforced with fibres the $F_{S L S} / F_{U L S}$ ratio varied from 0.70 to 0.97 . For both types of reinforcement $F_{S L S} / F_{U L S}$ ratio increased with the decrease of $\rho$. This shows that fibre reinforcement is very effective for the verifications of the design requirements imposed by the serviceability limit states, being this effectiveness as more pronounced as lower is $\rho$.

To evaluate the increase in terms of beams load carrying capacity provided by fibre reinforcement during the deflection process of the beams, the difference between the load carrying capacity of the SFRSCC and SCC beams, $\Delta F$, for each deflection value was evaluated. The relationship between the beam midspan deflection and $\Delta F / F$ ratio is represented in Fig. 5 in which $F$ is the load carrying capacity of the SCC beam at the same deflection where $\Delta F$ is evaluated. From the resulting curves it is apparent that the contribution of the fibres for the beam load carrying capacity starts from very early stages of the beam deformation just after the 
formation of incipient cracks. It is visible that $\Delta F / F$ increases up to the deflection corresponding to the peak load of the SFRSCC beams, having this increase attained a maximum value of $80 \%$. The decrease of $\Delta F / F$ ratio with the increase of $\rho$ is also apparent. For the beams reinforced with the minimum percentage of longitudinal reinforcement (L_6) the maximum value of the $\Delta F / F$ ratio occurred at a deflection of about the deflection corresponding to the serviceability limit states $\left(u_{S L S}=3.4 \mathrm{~mm}\right)$. In the series of beams reinforced with the other two percentages of longitudinal reinforcement, the $\Delta F / F$ ratio maintained almost constant in the deflection range between $20 \%$ and $200 \%$ of the $u_{S L S}$. This means that the benefits provided by fibre reinforcement for the serviceability limit states are as more pronounced as lower is $\rho$. In the case of being necessary to increase $\Delta F / F$ of beams of considerable $\rho$, a higher content of fibres needs to be applied, a subject treated in section 2.4. However, economic and technical aspects should be considered since besides the higher costs of the fibres (in comparison to the one of conventional steel bars), the costs derived from the necessity of using higher percentage of fine materials in the concrete composition when the content of fibres increases should be also taken into account.

The indices $I_{F(S L S)}$ and $I_{F(U L S)}$, representing the relative increase of the beam load carrying capacity provided by fibre reinforcement for the deflection corresponding to the serviceability limit states and for the deflection corresponding to the maximum load carrying capacity of SFRSCC beam, respectively, were determined from the following equations:

$$
I_{F}=\frac{F^{F R C}-F^{r e f}}{F^{r e f}} \times 100
$$

When $F^{F R C}$ and $F^{\text {ref }}$ correspond to $F_{S L S}$, it is evaluated the $I_{F}$ for the serviceability limit state analysis, $I_{F(S L S)}$, whereas the $I_{F}$ for the ultimate limit state analysis, $I_{F(U L S)}$, is obtained when the maximum forces ( $\left.F_{U L S}\right)$ are used in the evaluation of Eq. (1). The values of $I_{F(S L S)}$ and $I_{F(U L S)}$ are included in Table 4. These values indicate that the reinforcement of $45 \mathrm{~kg} / \mathrm{m}^{3}$ of fibres provided a gain in the load carrying capacity at the $u_{S L S}$ deflection that ranged from $29 \%$ to $77 \%$. This gain decreased with the increase of $\rho$. In terms of the maximum load, this tendency was almost the same, since this gain varied from $23 \%$ to $74 \%$, with an increase of the gain with the decrease of $\rho$. 


\subsubsection{Fibre distribution}

To evaluate the degree of heterogeneity on the fibre distribution in the plane of the beam, three core samples were extracted along its longitudinal axis. The fibre distribution in the depth of the beam was also estimated cutting these samples in three slices of equal thickness. According to the EFNARC (1996), the amount of fibres is calculated from

$$
Q_{f}=\frac{m_{f} \times 1000}{V_{c}}
$$

where $m_{f}$ is the weight (in grams) of the extracted fibres from the core sample and $V_{c}$ is the volume of the core sample in $\mathrm{cm}^{3}$. The content of fibres increased linearly in the depth of the beam, showing that even without external compaction the highest specific weight of the steel fibres, amongst the concrete constituents led to a tendency of an increase of the fibre content along the depth of the laminar structural element. However, due to the good homogeneity of the mix the fibre distribution does not show any tendency in the plan of the beam.

\subsection{Numerical Simulation}

Previous works (Barros et al. 2005, Barros and Fortes, 2005) have shown that, using a cross-section layered model that takes into account the constitutive laws of the intervenient materials and the cinematic and the equilibrium conditions, the deformational behaviour of structural elements failing in bending can be predicted from the moment-curvature relationship, $M-\varphi$, of the representative sections. To verify the capability of this model to predict the deformational behaviour of SFRSCC laminar structures, the tests carried out in the scope of the present work were simulated. To evaluate the $M-\varphi$ of the cross sections they were discretized in 3 layers with a thickness of $50 \mathrm{~mm}$. The tensile and compression longitudinal reinforcements were converted in steel layers with a thickness that provides the cross section area of the corresponding steel bars, placed at $20 \mathrm{~mm}$ and $130 \mathrm{~mm}$ from bottom surface of the cross section (see Fig. 1). The concrete tensile behaviour is simulated by the stress-strain diagram represented in Fig. 6. The values of the parameters defining the concrete constitutive model are included in Table 5. The values of the parameters defining the trilinear stress-strain softening diagram were obtained from inverse analysis, fitting the experimental results with the minimum error. The fracture energy, $G_{f}$, obtained for SFRSCC is about 44 times the $G_{f}$ of SCC, which is in agreement to the equation proposed by Barros and Figueiras (1999) for the estimation of $G_{f}$ of FRC reinforced with the type of fibres 
used in the present work. Furthermore, Table 5 also shows that the post-cracking residual strength of SFRSCC can be simulated by an almost constant stress of $0.65 \times \sigma_{c r}$, which is also in close agreement with the results obtained in previous research projects (Barros, 1995). As expected, for $45 \mathrm{~kg} / \mathrm{m}^{3}$ of steel fibres the tensile strength is only marginally increased.

The values of the parameters of the steel constitutive model are indicated in Table 6. Between yield initiation and ultimate strain a parabolic evolution of the stresses was assumed for this branch.

As Figs. 2, 3 and 4 show, this numerical strategy can predict the behaviour of elements failing in bending with high accuracy up to peak load. In the series without fibres, after the yield initiation of the longitudinal steel bars a moderate deflection hardening phase follows, which is the expected behaviour of elements with only ordinary reinforcement, since this phase depends on the behaviour of the steel bars. In the series reinforced with steel bars and steel fibres a significant deflection hardening phase occurred after the yield initiation of the longitudinal steel bars due to the contribution of the fibres bridging the formed cracks. After peak load these beams presented a clear structural softening phase due to concrete crushing in compression. The numerical model is not capable of capturing this phase since it is based on load control, in which an increment of load ( $\Delta \underline{F}$ ) is imposed to the beam and the bending moment $(M)$ in the middle section of the elements discretizing the beam is calculated. From the moment-curvature response of the section $(M-\varphi)$, the corresponding secant flexural stiffness $\left(E I_{s}\right)$ at this bending moment is determined $\left(E I_{s}=M / \phi\right)$ and used in a matrix displacement approach to obtain the increment of displacements $\left(\Delta \underline{U}=K_{s}^{-1} \Delta \underline{F}\right)$ for the imposed increment of forces $(\Delta \underline{F})$ ( $K_{s}$ is the secant stiffness matrix of the beam, resulting from the assemblage of the secant stiffness matrix of each element composing the beam). Since in this approach the bending moment at the cross section is the known variable, and considering that the $M-\varphi$ of the cross section of these beams has a softening branch, the secant flexural stiffness is not possible to determine beyond the curvature corresponding the peak moment. Therefore, this approach is only capable to determine the force-deflection response up to the peak load.

\subsection{Parametric studies}

Soranakom (2008) has recently developed a closed-form solution capable of determining the moment-curvature relationship of a cross section of a beam reinforced longitudinally with steel bars and made by SS-FRC. Recently Taheri et al. (2010) has adapted this model in order to simulate SS-FRC and SH-FRC reinforced 
concrete beams failing in bending, in which a platue residual strength is considered for FRC in tension by assigning a constant value of $\mu$ to the normalized residual strength of FRC $\left(\alpha_{1}=\alpha_{2}=\mu\right)$. In order to obtain a close form solution, the simplified constitutive laws for the concrete and steel bars represented in Fig. 7 were adopted. In this parametric study the influence of the following parameters that characterize the post crack residual strength of FRC will be assessed in terms of flexural capacity of elements failing in bending: $\beta_{1}$ parameter for (SS) FRC (the $\mu$ parameter is maintained constant and equal to $0.333 ; \mu$ parameter for SS-FRC (the $\quad \beta_{1}$ parameter is maintained constant and equal to 10.00); $\quad \beta_{1}$ parameter for (SH) FRC (the $\mu$ parameter is maintained constant and equal to 3); $\mu$ parameter for SH-FRC (the $\beta_{1}$ parameter is maintained constant and equal to 3.00). For each one of these parameters the influence of the steel reinforcement ratio, $\rho$, is also analyzed assuming values of $\rho$ varying from 0.0 (pure FRC) to $0.8 \%$, which cover most of the cases in which hybrid reinforcement (fibres and steel bars) is technically and economically justifiable.

The influence of each variable is evaluated in terms of normalized moment-curvature diagram $\left(M^{\prime}-\phi^{\prime}\right)$,

$$
\begin{gathered}
M=M^{\prime} M_{c r} \\
\phi=\phi^{\prime} \phi_{c r}
\end{gathered}
$$

where, $M^{\prime}$ and $\phi^{\prime}$ are the normalized moment and curvature, and $M_{c r}$ and $\phi_{c r}$ are the cracking moment and the corresponding curvature calculated for a rectangular section from the following equations:

$$
\begin{aligned}
& M_{c r}=\frac{1}{6} b d^{2}\left(E \varepsilon_{c r}\right) \\
& \phi_{c r}=\frac{2 \varepsilon_{c r}}{d}
\end{aligned}
$$

Using the moment-curvature relationship the beam's normalized force-deflection response $\left(p^{\prime}-u^{\prime}\right)$ of a statically determinate element failing in bending will be determined using the algorithm described in (Barros and Fortes, 2005), where $p^{\prime}=p / p_{c r}$ and $u^{\prime}=u / u_{c r}$, being $p_{c r}$ and $u_{c r}$ the beam distributed load at FRC crack initiation and the corresponding deflection, respectively. $p_{c r}$ is the $p$ load when in the centre of the beam the bending moment coincides with $M_{c r}$. 
For the parametric study, a simply supported beam of $5 \mathrm{~m}$ span length subject to a constant distributed load $(p)$ is considered. The geometry characteristics of the cross section of this beam and the values that define the diagrams representing the constitutive laws of the intervening materials are indicated in Table7.

The results of the parametric study are represented in Figs. 8 to 11. As expected, for statically determinate elements the variation of $p^{\prime}-u^{\prime}$ follows closely the variation of $M^{\prime}-\phi^{\prime}$.

\section{Influence of $\beta_{1}$ parameter for SS-FRC}

Fig. 8a represents the effectiveness of $\beta_{1}$ parameter in terms of the cross section resisting bending moment, $\Delta M / M_{\min }$, where $\Delta M=M_{\max }-M_{\min }$ is the difference between the maximum resisting bending moment ( $\left.M_{\max }\right)$ which occurs for $\beta_{1}=15\left(M_{\max }=M_{\beta_{1}=15}\right)$ and the minimum resisting bending moment $\left(M_{\min }\right)$ which occurs for $\beta_{1}=1.01\left(M_{\min }=M_{\beta_{1}=1.01}\right)$. Fig. $8 \mathrm{~b}$ is illustrated the effectiveness of $\beta_{1}$ parameter in terms of beam's load carrying capacity ( $\Delta p / p_{\min }$, where $\Delta p=p_{\max }-p_{\min }$ with $P_{\max }=P_{\beta_{1}=15}$ and $\left.P_{\min }=P_{\beta_{1}=1.01}\right)$. From Fig. 8 it is clearly visible that the effectiveness in terms of $\Delta M / M_{\min }$ and $\Delta p / p_{\min }$ provided by the increase of $\beta_{1}$ decreases with the increase of $\rho$ (if the remaining FRC parameters are maintained constant). It is also visible that for statically determinate elements the effectiveness of increasing $\beta_{1}$ parameter is higher in terms of cross section resisting bending moment than in terms of load carrying capacity of the beam. The maximum effectiveness in terms of cross section resisting bending moment occurred for the interval of $\phi$ varying between $2.4(\rho=0.8)$ and $4.2(\rho=0.0)$, while in terms of beams load carrying capacity occurred in the range of $u^{\prime} \in[2.6(\rho=0.8)-5.1(\rho=0.0)]$. According to the Eurocode 2 (prEN 1992-1-1 2002), the maximum deflection for serviceability limit states $\left(u_{S L, \text {, max }}\right.$ ) should be restricted to the interval $L / 250-L / 500$ (depending on the type and utility of a structure), where $L$ is the beam's span length. For the present beam $u_{S L S, \max } \in[10-20] \mathrm{mm}$, which is approximately 10 to 20 times higher than the $u_{c r}\left(u_{S L, \text { max }} / u_{c r} \in[10-20]\right)$. Taking into account these results it can be concluded that the increase of $\beta_{1}$ is quite effective in terms of serviceability limit states. 


\section{Influence of $\mu$ parameter for SS-FRC}

Figs. $9 \mathrm{a}$ and $9 \mathrm{~b}$ represent the influence of the post-cracking residual strength parameter, $\mu$, of SS-FRC in terms of $\Delta M / M_{\min }$ and $\Delta p / p_{\min }$ responses respectively. In terms of the load carrying capacity of statically determinate elements failing in bending, Fig. $9 \mathrm{~b}$ evidences that the effectiveness of increasing the $\mu$ of SSFRC is smaller when $\rho=0$, than when the beams have the minimum reinforcement ratio that assures a stabilized crack propagation, $\rho_{\text {stab }}$ (about $\rho_{\text {stab }} \cong 0.2 \%$ ). For SS-FRC beams without conventional reinforcement, apart the case of $\mu=0.99$, the $M^{\prime}-\phi^{\prime}$ curve of the remaining cases has a softening branch, leading to a marginal increase in terms of beam's load carrying capacity. For beams with $\rho=\rho_{\text {stab }}$, the increase of $\mu$ has the most favourable impact in terms of $\Delta M$ and $\Delta p$. However, for beams with $\rho>\rho_{\text {stab }}$, the effectiveness of increasing the $\mu$ parameter in terms of $\Delta M / M_{\min }$ and $\Delta p / p_{\min }$ decreases with the increase of $\rho$.

\section{Influence of $\alpha$ parameter for SH-FRC}

Figs. 10a and 10b represent the influence of $\beta_{1}$ parameter of SH-FRC in terms of $\Delta M / M_{\text {min }}$ and $\Delta p / p_{\text {min }}$ responses respectively. It is visible that the $M_{\max }-M_{\min }\left(=M_{\beta_{1}=5}-M_{\beta_{1}=20}\right)$ and $P_{\max }-P_{\min }\left(=P_{\beta_{1}=5}-P_{\beta_{1}=20}\right)$ decreases with the increase of $\rho$ (maintaining the remaining FRC properties).

\section{Influence of $\mu$ parameter for SH-FRC}

Fig. 11 shows that the effectiveness of $\mu$ of SH-FRC in terms of $\Delta M / M_{\min }$ and $\Delta p / p_{\min }$ decreases with the increase of $\rho$. However, the relatively high costs of a fibre reinforcement system that assures SH characteristics to a FRC in order to provide the same $M^{\prime}$ and $p^{\prime}$ of a conventional reinforcement systems is still only justifiable in very specific structural systems, such is the case of elements of geometric complexity, elements that corrosion of steel bars cannot occur, and in cases where time consuming to prepare and apply conventional reinforcement systems has significant impact on the final costs of the structure.

\section{Steel fibre reinforced concrete for RC elements failing in shear}




\subsection{Introduction}

The application of stirrups in concrete elements, especially in those of hollow section or composed of thin walled components, mobilize significant labour time, resulting in important financial charges. In structural concrete elements of buildings in seismic risk zones, the density of steel stirrups and hoops may difficult to obtain the desired concrete quality. Due to this type of reasons, the substitution of stirrups per steel fibres has been studied for several researchers (Casanova 1995, Casanova et al. 2000, Barragan 2002, Gettu et al. 2004). Casanova (1995) concluded that steel fibres may substitute significant percentages of steel stirrups, especially when high strength concrete is used, since the fibre reinforcement mechanisms increase with the increase of the concrete strength, as long as fibre rupture is avoided.

Experimental results evidenced that beams reinforced only with steel fibres showed a similar, or even better, post cracking behaviour than reference beams with the minimum amount of steel stirrups (Meda et al. 2005). When used in beams reinforced with steel stirrups, steel fibres significantly improved the shear resistance. Steel fibres also reduce the width of shear cracks, thus improving the concrete durability and structural integrity (Meda et al. 2005).

\subsection{Experimental program}

\subsubsection{Test series, specimens, mix compositions, test setup and monitoring system}

Six series of High Strength Concrete (HSC) of strength classes 50MPa and 70MPa were developed by varying the dosage of steel fibres $\left(0,60\right.$ and $\left.75 \mathrm{~kg} / \mathrm{m}^{3}\right)$. The specimens were labelled as $f_{c m i}{ }_{-} \mathrm{FCj}$, where "i" is the concrete compressive strength class of the specimen and " $\mathrm{j}$ " indicates the dosage of fibre (in $\mathrm{kg} / \mathrm{m}^{3}$ ). For instance $f_{c m 50}$ Nofibres represent the specimens of 50MPa concrete compressive strength class without fibres, while $f_{c m 70} F C 75$ represent the specimens of 70MPa concrete compressive strength reinforced with $75 \mathrm{Kg} / \mathrm{m}^{3}$ steel fibres. Table 8 includes the six designed mix compositions. The steel fibres already presented in the previous section were also used in this experimental program. For each mix composition three cylinders (150 $\mathrm{mm}$ diameter and $300 \mathrm{~mm}$ height), three cubes (of $150 \mathrm{~mm}$ edge), and four prismatic specimens $(600 \times 150 \times 150$ $\mathrm{mm}^{3}$ ) were cast and tested to assess the compression and bending behaviour of the developed concrete compositions. To evaluate the influence of the percentage of fibres in shear resistance of HSC elements, three 
point bending tests with shallow beams of $800 \times 170 \times 150 \mathrm{~mm}^{3}$ dimensions were carried out (distance between supports equal to $720 \mathrm{~mm}$ ).

The experimental program was composed of twenty four shallow beams, four beams for each series: two of plain concrete and two with two steel bars of $20 \mathrm{~mm}$ diameter as the tensile longitudinal reinforcement, which is a relatively high reinforcement ratio in order to force the occurrence of shear failure in these beams. The geometry of the beams and the arrangement of the reinforcement are represented in Fig. 12.

The tests were executed with a servo-controlled equipment of maximum load capacity of $300 \mathrm{kN}$. The tests were controlled by the displacement transducer of the actuator, at a displacement rate of $3 \mu \mathrm{m} / \mathrm{s}$, using for this purpose the LVDT placed at the midspan of the beam.

\subsubsection{Results and analysis}

\section{Compression behaviour}

The compressive strength of each series of High Strength Steel Fibre Reinforced Concrete (HSSFRC) was obtained after 14 days of concrete casting operations. As expected, all HSC presented similar compressive behaviour, with a small increase on the strength with the increase of the fibre content. It was observed that the residual strength has increased with the fibre content. The main obtained results are included in Table 9. Each result is the average of three tests. The average compressive strength was a little bit lower than the target values.

\section{Flexural behaviour}

Apart the geometry of the notch in the prismatic specimens, the remaining RILEM TC 162-TDF recommendations (2003) for the characterization of the flexural behaviour of SFRC were adopted. In fact, the preliminary specimens were tested with a notch of $2-3 \mathrm{~mm}$ thick and $25 \pm 1 \mathrm{~mm}$ depth, as recommended by RILEM TC, but several cracks were formed outside the notched section. According to RILEM TC 162-TDF these tests are not valid because the energy dissipated in the fracture process cannot be accurately evaluated, since the real area of the cracks formed is almost impossible of being determined. The depth of the notch that assured the formation of a single crack in the notched plan was determined from experimental trials, having been obtained a notch depth of $74 \mathrm{~mm}$, which is almost half the depth of the specimen cross section. The forcedeflection curves, $F-u$, obtained in the tested series are depicted in Fig. 13. Each curve is the average of the $F-u$ relationship recorded in three specimens. The series without fibres showed a deflection softening 
behaviour, with abrupt load decay after peak load. The series with fibres presented a pronounced deflection hardening and ductile behaviour. After the crack initiation a hardening phase happened in all series reinforced with fibres. The softening phase has started for the identical values of deflection (around $2.0 \mathrm{~mm}$ ) in all series. The influence of the fibre dosage on the post-cracking flexural strength was higher in the $f_{c m 50}$ series. In fact, the difference between the series with $60 \mathrm{~kg}$ and $75 \mathrm{~kg}$ of fibres per cubic meter of concrete was more pronounced in $f_{c m 50}$ than in the $f_{c m 70}$ series. The softening branch in the $f_{c m 70}$ series with $60 \mathrm{~kg} / \mathrm{m}^{3}$ of steel fibres has more pronounced load decay than in all the other series. This shows that the same dosage of steel fibres may cause different levels of reinforcement effectiveness in concretes of different strength class. Due to the better fibre-matrix bond properties provided by $f_{c m 70}, 60 \mathrm{~kg} / \mathrm{m}^{3}$ assured a peak load higher than the one registered in the $f_{c m 50}$ with the same content of fibres. However, since the number of fibres crossing the fracture surface is almost the same in both series and the energy accumulated up to peak load of the $f_{c m 70}$ is higher than in $f_{c m 50}$, the load decay in the softening phase of $f_{c m 70}$ was more pronounced than in $f_{c m 50}$ series.

\section{Behaviour in shear}

The load vs midspan deflection curves obtained from the three point loading tests carried out with the shallow beams are presented in Fig. 14. Table 10 includes the force at a deflection corresponding to the serviceability limit state (L/400 with $\mathrm{L}$ being the beam span length in $\mathrm{mm}$ ), $F_{S L S}$, and to the ultimate limit state (maximum force), $F_{U L S}$, registered in the tests. To estimate the contribution of fibre reinforcement at serviceability and at ultimate limit states, the values of $I_{F(S L S)}$ and $I_{F(U L S)}$, established in Eq. (1), were determined. These values are indicated in Table 11 from which it can be concluded that fibre reinforcement provided a contribution for the load carrying capacity of the shallow beams, at deflection SLS analysis, ranging from $43 \%$ to $72 \%$, while for the ULS analysis, the fibre reinforcement effectiveness varied from $80 \%$ to $118 \%$.

\section{Failure modes}

As Fig. 15 shows all tested RC beams failed in shear. However, the number of flexural cracks formed up to the ocurrence of the shear failure crack increased with the increase of the content of steel fibres. Furthermore, it is visible that the inclination of the shear failure crack (angle of the shear crack plan with the beam longitudinal axis) decreased with the increase of the content of fibres, which justifies the resulting benefits of fibre 
reinforcement, since larger area of crack bridged by fibres was mobilized and more favorable inclination of the fibre resisting tensile force was obtained for the shear resistance. Moreover, due to the crack opening arrestment offered by fibres bridging the shear crack plans, a diffuse crack pattern occurred in the vicinity of the shear failure crack, contributing for the increase of energy dissipation and for the more ductile failure mode observed in HSSFRC beams, in comparison to HSC beams (see also Fig. 14).

\subsection{Predictive performance of the RILEM TC 162-TDF model}

As a result of the Brite-Euram Project (2002), where numerical and experimental research was developed, RILEM TC 162-TDF (2003) proposed a formulation in the close format of CEB-FIP Model Code (1993). According to this formulation the shear resistance of a concrete element reinforced with steel stirrups, steel fibres and ordinary longitudinal reinforcement is given by:

$$
V_{R d 3}=V_{c d}+V_{f d}+V_{w d}
$$

where $V_{c d}$ and $V_{w d}$ represent the contribution of concrete and steel stirrups, respectively, for the shear resistance determined according to the CEB-FIP Model Code (1993), and $V_{f d}$ is the contribution of fibre reinforcement:

$$
V_{f d}=0.7 k_{f} k_{1} \tau_{f d} b d \quad[\mathrm{~N}]
$$

where $k_{f}$ and $k_{1}$ are factors that for the cross sections of the shallow beams assume a unitary value, $b$ and $d$ are the width and the depth of the cross section, and

$$
\tau_{f d}=0.12 f_{e q k, 3}\left[\mathrm{~N} / \mathrm{mm}^{2}\right]
$$

or

$$
\tau_{f d}=0.12 f_{R k, 4}\left[\mathrm{~N} / \mathrm{mm}^{2}\right]
$$

where $f_{e q k, 3}$ and $f_{R k, 4}$ are respectively the characteristic value of the equivalent and residual flexural tensile strength parameters determined under the recommendations of RILEM TC 162-TDF (2003).

Applying this formulation to the experimental program carried out in the present work, the contribution of steel fibres for the concrete shear resistance was evaluated. The obtained values included in Table 12 show that the smaller safety factor in series reinforced with fibres was 1.88 . It should be mentioned that in the calculations of 
Table 12 average values were used for the equivalent and residual flexural strengthening parameters, since the use of characteristics values lead to too high safety factors due to the relatively high coefficient of variation $(\mathrm{COV})$ that was obtained for these parameters. A possible alternative to decrease the COV of these parameters is the use of experimental programs composed of 10 to 12 bending specimens (in the present experimental program the series of notched beam tests were composed of three specimens).

\subsection{Numerical simulations}

Previous research (Pereira et al. 2008) indicated that fracture mode I propagation of SFRC can be simulated by the tri-linear softening diagram represented in Fig. 16), whose parameters (mode I fracture energy, $G_{f}^{I}$, and values of $\varepsilon_{n, i}^{c r}$ and $\sigma_{n, i}^{c r}$ that define the shape of the softening diagram) can be obtained performing inverse analysis with the force-deflection data registered in three-point notched beam bending tests carried out according to the RILEM TC 162-TDF recommendations.

To simulate the crack shear sliding, a shear retention factor $(\beta)$ is currently used (Sena 2004). With this approach the increment of shear stress $\left(\Delta \tau_{n t}^{c r}\right)$ transferred between the crack planes decreases with the increase of the crack normal strain ( $\varepsilon_{n}^{c r}$ ), according to an assumed relationship between $\beta$ and $\varepsilon_{n}^{c r}$, like the following one:

$$
\beta=\left(1-\varepsilon_{n}^{c r} / \varepsilon_{n, u}^{c r}\right)^{q}
$$

where $q$ defines the decrease level of $\beta$ with the increase of the crack normal strain. In structures that do not fail by the formation of a critical shear crack this strategy provides simulations with reasonable accuracy. However, to capture the structural softening of structures failing in shear, a softening crack shear stress vs. crack shear strain relationship, like the one represented in Fig. 17, should be used. In this figure, $\tau_{p}^{c r}$ is the concrete shear strength and $G_{f}^{I I}$ is the mode II fracture energy (Rots and de Borst 1987). In the performed analysis the same crack band width $\left(l_{b}\right)$ was assumed for either the fracture mode I and fracture mode II diagrams. In order to obtain results independent of the finite mesh refinement, the value of $l_{b}$ was assumed equal to the square root of the area of the sampling points of the finite elements (Bazant and Oh 1983).

To determine the values of the parameters that define the fracture mode I propagation an inverse analysis was performed using the force-deflection relationship $(\mathrm{F}-\mathrm{u})$ obtained in the notched beam bending tests. The 
stress-crack opening diagram represented in Fig. 18 was used to simulate the crack propagation. This diagram is defined from the stress crack initiation, $\sigma_{n 1}^{c r}$, the mode I fracture energy $\left(G_{f}^{I}\right.$, which is the area under the $\sigma-w$ diagram) and the two par of $\left(\xi_{i}, \alpha_{i}\right)$ points. According to the inverse analysis, the values of these parameters are obtaining by fitting the $\mathrm{F}-\mathrm{u}$ curves with the minimum error of the parameter err $=\left|A_{F-u}^{\mathrm{exp}}-A_{F-u}^{\text {num }}\right| / A_{F-u}^{\mathrm{exp}}$ where $A_{F-u}^{\mathrm{exp}}$ and $A_{F-u}^{\text {num }}$ are the areas below the experimental and the numerical $\mathrm{F}-\mathrm{u}$ curve, respectively.

Fig. 19 shows the finite element mesh used in the inverse analysis. 2D line interface finite elements were located in the specimen's symmetry axis (Sena et al. 2004). In the remaining parts of the specimen linear eight-node Serendipity plane-stress elements were used. Gauss-Lobatto integration scheme (Schellekens 1990) with three integration points (IP) was used for the 2D line interface finite elements, while Gauss-Legendre integration scheme with $2 \times 2$ IP was used for the eight-node elements. The values of the concrete Young's Modulus, $E$, considered in the inverse analysis are indicated in Table 9.

The adequacy of the numerical strategy adopted is shown in Fig. 20, revealing that the proposed trilinear $\sigma-w$ diagram is capable of predicting the post-cracking behaviour of the tested specimens with enough accuracy. The values defining the $\sigma-w$ diagram obtained from inverse analysis are included in Table 13 .

The performance of the crack shear softening model was assessed by the simulation of the experimental tests with shallow beams failing in shear. A finite element mesh of 406 plane stress elements of 8 nodes, with a Gauss-Legendre $2 \times 2$ integration scheme, was used in these simulations. The steel bars were simulated by perfectly bonded two nodes elements with 2 IP. Due to the structural symmetry of the beams, only half part of the beam was simulated. The values of the fracture mode I parameters of the smeared crack consitutive model used in the simulations were the same derived from the inverse analysis (see Table 13).

Using these values for modelling the fracture mode I propagation it was verified that the model did not match the experimental results with good accuracy. In a previous work (Barros et al. 2004) dedicated to the numerical simulation of FRC beams failing in shear, it was already observed that, with the values obtained from inverse analysis for the characterization of the fracture mode I constitutive law, the prediction performance of the model was deficient. In structures failing in shear, the fracture mode I properties are affected by the crack sliding components (Nooru 1992, Divakar et al. 1987), therefore a crack constitutive model based on independent properties for mode I and mode II fracture modes, such is the case of the present model, can only capture the 
behaviour of these type of structures if the mode I fracture parameters are adapted. Since specific research for the assessment of the fracture parameters of FRC in mixed mode fracture propagation does not exist, the values of the fracture mode I parameters included in Table 14 were obtained from trial-error approach. This indicates the necessity of doing research in this topic for a scientific-based determination of the fracture parameters.

The approach for simulating the fracture mode II is also another important aspect for the numerical prediction of the failure mode in this type of structures. In fact, when the conventional shear retention factor is used (for any type of $q$ parameter in Eq. (10)), the model predicted a flexural failure mode with a load carrying capacity for the beams much higher than the ones recorded in the experimental tests (Fig. 21). However, by using a shear softening law, characterized by the fracture mode II parameters included in Table 13, the model captured the peak load with high accuracy as well as the structural softening behaviour and the shear failure mode (Fig. 21). Since experimental data to characterize the crack shear softening diagram are not available, the values of $\tau_{p}^{c r}$ and $G_{f}^{I I}$ were estimated from back fitting analysis, based on the criteria of simulating with high precision the peak load of the tested beams (Fig. 21).

\section{Conclusions}

The first part of the paper was dedicated to the assessment of the benefits of using a constant content of steel fibres in shallow beams reinforced with distinct longitudinal reinforcing ratios $(\rho)$. From the force-deflection relationships obtained in three series of shallow beams, it was concluded that $45 \mathrm{~kg} / \mathrm{m}^{3}$ of steel fibres contributed significantly for the beams load carrying capacity from the incipient crack formation stage, i.e., from a deflection level that is lower than $1 / 10$ of the deflection corresponding to the serviceability limit states. The increase in terms of beam's load carrying capacity provided by fibre reinforcement was as significant as lower was $\rho$. At the deflection corresponding to the serviceability limit states, $45 \mathrm{~kg} / \mathrm{m}^{3}$ of the used steel fibres (hooked end steel fibres of an aspect-ratio of 80) provided an increase of the beam load carrying capacity that ranged from $29 \%$ for $\rho=0.56$ up to $77 \%$ for $\rho=0.2$. In terms of the beam maximum load carrying capacity, this content of steel fibres provided an increase that varied from $23 \%$ for $\rho=0.56$ up to $74 \%$ for $\rho=0.2$. 
A cross section layer model was used to determine the moment-curvature relationship, $M-\varphi$, of the representative sections of the tested shallow beams. This simple numerical strategy was able to predict, with enough accuracy, the load-deflection response registered experimentally.

The second part of the paper was dedicated to the assessment of the benefits of steel fibres for the shear resistance of shallow beams failing in shear. The experimental program evinced that steel fibre reinforcement provides a significant contribution for the shear resistance of high strength concrete laminar structures. A content of $60 \mathrm{~kg} / \mathrm{m}^{3}$ of hooked end steel fibres (the same type used in all the research program) provided an increase on the shear resistance that varied from $88 \%$ to $92 \%$ for shallow beams of a concrete with an average compressive strength ranging from 50 to $70 \mathrm{MPa}$. For $75 \mathrm{~kg} / \mathrm{m}^{3}$ of these steel fibres, this increase varied from $102 \%$ to $118 \%$

The formulation proposed by RILEM TC 126 -TDF for the evaluation of the contribution of the fibre reinforcement for the shear resistance of concrete beams provided a safety factor of about 2.18 , while a safety factor of about 1.66 was obtained in the beams without steel fibres.

For the FEM-based numerical simulation of the shallow beams failing in shear, in a first attempt, the mode I fracture parameters were obtained from inverse analysis, fitting the force-deflection relationships recorded in the notched beam bending tests carried out for the flexural characterization of the developed HSFRC. This methodology was unable of capturing the deformational behaviour of the beams with enough accuracy. It was also verified that using the shear retention factor for modelling the fracture mode II propagation, a flexural failure mode was predicted numerically, with a maximum load capacity for the beams higher than the one registered experimentally. Simulations with good accuracy were obtained adjusting the values that define the fracture mode I propagation and using a shear softening diagram for modelling the crack sliding. This indicates that more research should be carried out in order to define the crack constitutive law for the mixed-mode fracture in FRC.

\section{Acknowledgements}

The study presented in this paper is part of the research project titled "DURCOST - Innovation in reinforcing systems for sustainable pre-fabricated structures of higher durability and enhanced structural performance" with reference number of PTDC/ECM/105700/2008. The authors also thank the collaboration of the following 
companies: Bekaert for supplying the steel fibers, Secil/Unibetão for providing the Cement, SIKA for supplying the superplasticizers; CiviTest for the production of SFRC specimens.

\section{References}

ACI 318 (2008), "Building Code Requirements for Structural Concrete and Commentary, Appendix A, Strutand-Tie Models", American Concrete Institute, Farmington Hills.

Barragán, B.E. (2002), "Failure and tougness of steel fiber reinforced concrete under tension and shear", $P h D$ Thesis, Universitat Politecnica de Catalunya (UPC) Bercelonatech, Barcelona, March.

Barros, J. A. O. (1995), "Behaviour of fibre reinforced concrete - experimental analysis and numerical simulation”, PhD Thesis, Dep. Civil Eng., Faculty of Eng., Porto University, 502 p, (in Portuguese).

Barros, J. A. O. and Figueiras, J. A. (1998), "Experimental behaviour of fiber concrete slabs on soil", J. Mechanics of Cohesive-frictional Materials, 3, 277-290.

Barros, J. A. O. and Figueiras, J. A. (1999), "Flexural behavior of steel fiber reinforced concrete: testing and modelling”, J. Materials in Civil Engineering, ASCE, 11(4), 331-339.

Barros, J. and Antunes, J., (2003), "Experimental characterization of the flexural behavior of steel fiber reinforced concrete according to RILEM TC 162-TDF recommendation," RILEM 162-TDF Workshop, Bochum, Germany, 77-90.

Barros, J.A.O., Gettu, R. and Barragan, B.E. (2004), "Material Nonlinear analysis of Steel fibre reinforced concrete beams failing in shear", Proceeding of 6th International RILEM Symposium on fibre reinforced concrete - BEFIB 2004, Edts. M. di Prisco, R. Felicetti, G.A. Plizarri, 1, 711-720, 20-22, September.

Barros, J. A. O., Cunha, V. M. C. F., Ribeiro, A. F. and Antunes, J. A. B. (2005), "Post-Cracking Behaviour of Steel Fibre Reinforced Concrete”, RILEM Materials and Structures Journal, 38(275), 47-56.

Barros, J.A.O. and Fortes, A.S. (2005), "Flexural Strengthening of Concrete Beams with CFRP Laminates Bonded into Slits", J. Cement and Concrete Composites, 27(4), 471-480.

Barros, J.A.O., Pereira, E.B. and Santos, S.P.F. (2007), "Lightweight panels of steel fiber reinforced selfcompacting concrete", J. Materials in Civil Engineering, 19(4), 295-304.

Barros, J.A.O., di Prisco, M. and di Prisco, C. (2009), "Modelling FRC infrastructures taking into account the soil-structure interaction", Conference on the Numerical Methods in Engineering, Barcelona, 29 June to 2 
July.

Bazant, Z.P. and Oh, B.H. (1983), "Crack band theory for fracture of concrete", Materials and Structures, RILEM, 16(93), 155-177.

Brite Euram / Swedish Cement and Concrete Research Institute, (2002), Brite-Euram. Rational Production and Improved Working Environment through using Self Compacting Concrete - Brite-Euram project, BRPRCT96-0366. Technical report.

Casanova, P. (1995), "Bétons de fibres métalliques: du materiaux à la structure", PhD Thesis, École Nationale des Ponts et Chaussées, (in French).

Casanova, P., Rossi, P. and Schaller, I. (2000), "Can steel fibres replace transverse reinforcement in reinforced concrete beams?", ACI Material J., 94, 341-354.

CEB-FIP Model Code, Comite Euro-International du Beton, Bulletin d'Information (1993), nº 213/214.

Chiaia, B., Fantilli, A.P. and Vallini, P. (2009), "Evaluation of crack width in FRC structures and application to tunnel linnigs", J. Materials and Structures, 43(3), 339-351, April.

de Borst, R. (2002). "Fracture in quasi-brittle materials: a review of continuum damage-based approaches", Eng Fract Mech, 69, 95-112.

di Prisco, M., Felicetti, R. and Plizzari, G.A. (2004), "Precast SFRC Elements: from Material Properties to Structural Applications", Proceeding of 6th RILEM Symposium on Fibre-Reinforced Concretes (FRC) BEFIB, 20-22 September, Varenna, Italy.

Divakar, M.P., Fafitis, A. and Shah, S.P. (1987), "Constitutive model for shear transfer in cracked concrete", J. Struct. Eng., ASCE, 113(5), 1047-1062, May.

EFNARC, Specification and Guidelines for Self-Compacting Concrete (2002), ISBN, 09539733 4 4, 32 pp.

EN197-1:2000 (2000), Cement. Composition, specifications and conformity criteria for low heat common cements, ISBN: 058036456 9, 52pp.

EFNARC (1996), European Federation of Producers and Applications of Specialist Products for Structures, European Specification for Sprayed concrete, Loughborough University, 1996

Eurocode 2. (2004), Design of concrete structures - Part 1-1: General rules and rules for buildings. Comité Européen de Normalisation (CEN), EN 1992-1-1:2004: E, Brussels.

Gettu, R., Barragán, B., García, T., Ramos, G., Fernández, C. and Oliver, R. (2004), "Steel Fiber Reinforced Concrete for the Barcelona Metro Line 9 Tunnel Lining", Proceeding of 6th RILEM Symposium on Fibre- 
Reinforced Concretes (FRC) - BEFIB, 20-22, September, Varenna, Italy. (Invited lecturer)

Meda, A., Minelli, F., Plizzari, G.A. and Riva, P. (2005), "Shear behaviour of steel fibre reinforced concrete beams", J. Materials and Structures, 38(3), 343-353, April.

Naaman, A.E. and Reinhard, H.W. (2005), "Proposed classification of HPFRC composites based on their tensile response", Proceedings of 3rd international Conference on Construction materials, Performance, Innovations and Structural Implications (ConMat'05) and Mindess Symposium, p. 458, Eds, N., Banthia, A.B., T.Uomoto and Shah, S., University of British Columbia, Vancouver, Canada.

Nooru, M.B.-Mohamed (1992), "Mixed-mode fracture of concrete: an experimental approach", PhD Thesis, Delft University of Technology.

Okamura, H. (1997), "Ferguson Lecture for 1996: Self-compacting high-performance concrete", Concrete International, ACI, 19(7), 50-4,.

Pereira, E. N. B. (2006), Steel Fibre Reinforced Self-compacting Concrete: from material to mechanical behaviour", dissertation for Pedagogical and Scientific Aptitude Proofs, Department Civil Engineering, University of Minho, 188 pp, http://www.civil.uminho.pt/composites.

Pereira, E.B., Barros, J.A.O. and Camões, A.F.F.L. (2008), "Steel fiber reinforced self-compacting concrete experimental research and numerical simulation", J. Structural Engineering, 134(8), 1310-1321, August.

Pereira, E.B., Fischer, G., Barros, J.A.O. and Lepech, M. ( 2010), “Crack formation and tensile stress-crack opening behavior of fiber reinforced cementitious composites (SHCC)", Proceedings of FraMCoS-7, Eds: B. H. Oh, O. C. Choi \& L. Chung, Jeju, Korea, May 23-28.

prEN 1992-1-1, Eurocode 2: Design of concrete structures - Part 1, (2002), General rules and rules for buildings, April.

RILEM TC 162-TDF, Test and design methods for steel fibre reinforced concrete $-\sigma-\varepsilon$ design method - Final Recommendation (2003), Materials and Structures, 36, 560-567, October.

Roshani, D. (1996) "Shear Capacity of Steel Fiber Reinforced Concrete Beams”, MSc Thesis, Göteborg University.

Rots, J.G. and de Borst, R. (1987), “Analysis of mixed mode fracture in concrete”, J. Engineering Mechanics, ASCE, 113(11), 1739-1758.

Schellekens, J.C.J. (1990). "Interface elements in finite element analysis”, Report, No. $25290-517$ (TU-Delft), Delft University of Technology, The Netherlands, $82 \mathrm{pp}$. 
Sena-Cruz, J.M., Barros, J.A.O., Ribeiro, A.F., Azevedo, A.F.M. and Camões, A.F.F.L. (2004), “Stress-crack opening relationship of enhanced performance concrete", 9th Portuguese Conference on Fracture, ESTSetúbal, Portugal, 395-403, 18-20 February.

Sena Cruz, J.M. (2004), "Strengthening of concrete structures with near-surface mounted CFRP laminate strips", PhD Thesis, Dep. Civil Eng., University of Minho, http://www.civil.uminho.pt/composites

Soranakom, C. and Mobasher, B. (2008), "Correlation of tensile and flexural response of strain softening and strain hardening cement composites", Cement \& Concrete Composites, 30, 465-477.

Soranakom C. (2008), "Multi scale modeling of fibre and fabric reinforced cement based composites", $P h D$ thesis, Arizona State University.

Swamy, R.N. and Al-Ta'An, S.A. (1981), "Deformation and Ultimate Strength in Flexure of Reinforced Concrete Beams made with Steel Fibre Concrete”, ACI Journal, Proceedings, 78(5), Sept-Oct., 395-405.

Taheri, M., Barros, J.A.O. and Salehian, H. (2010), “A design model for strain-softening and strain-hardening fiber reinforced elements reinforced by longitudinal steel bars failing in bending - implementation and parametric studies", Technical report 10-DEC/E-06, Dep. Civil Eng., School Eng. University of Minho, March.

Vandewalle, L. (2000), "Cracking behaviour of concrete beams reinforced with a combination of ordinary reinforcement and steel fibers", J. Materials and Structures, 33(3), 339-351, April.

$\begin{array}{ll}\text { Notation } & \\ a & =\text { shear span } \\ A_{F-u}^{\exp } & =\text { the area below experimental } \mathrm{F}-\mathrm{u} \text { curve } \\ A_{F-u}^{\text {num }} & =\text { area of longitudinal reinforcement } \\ A_{s l}^{+} & =\text {cross section width } \\ b & =\text { cement } \\ C & =\text { crashed calcareous } 6-14 \mathrm{~mm} \\ C G-1 & =\text { crashed calcareous } 14-20 \mathrm{~mm} \\ C G-2 & =\text { coarse river sand } \\ C S & =\text { cross section depth } \\ d & =\text { internal arm of reinforcement } \\ d^{\prime} & \end{array}$




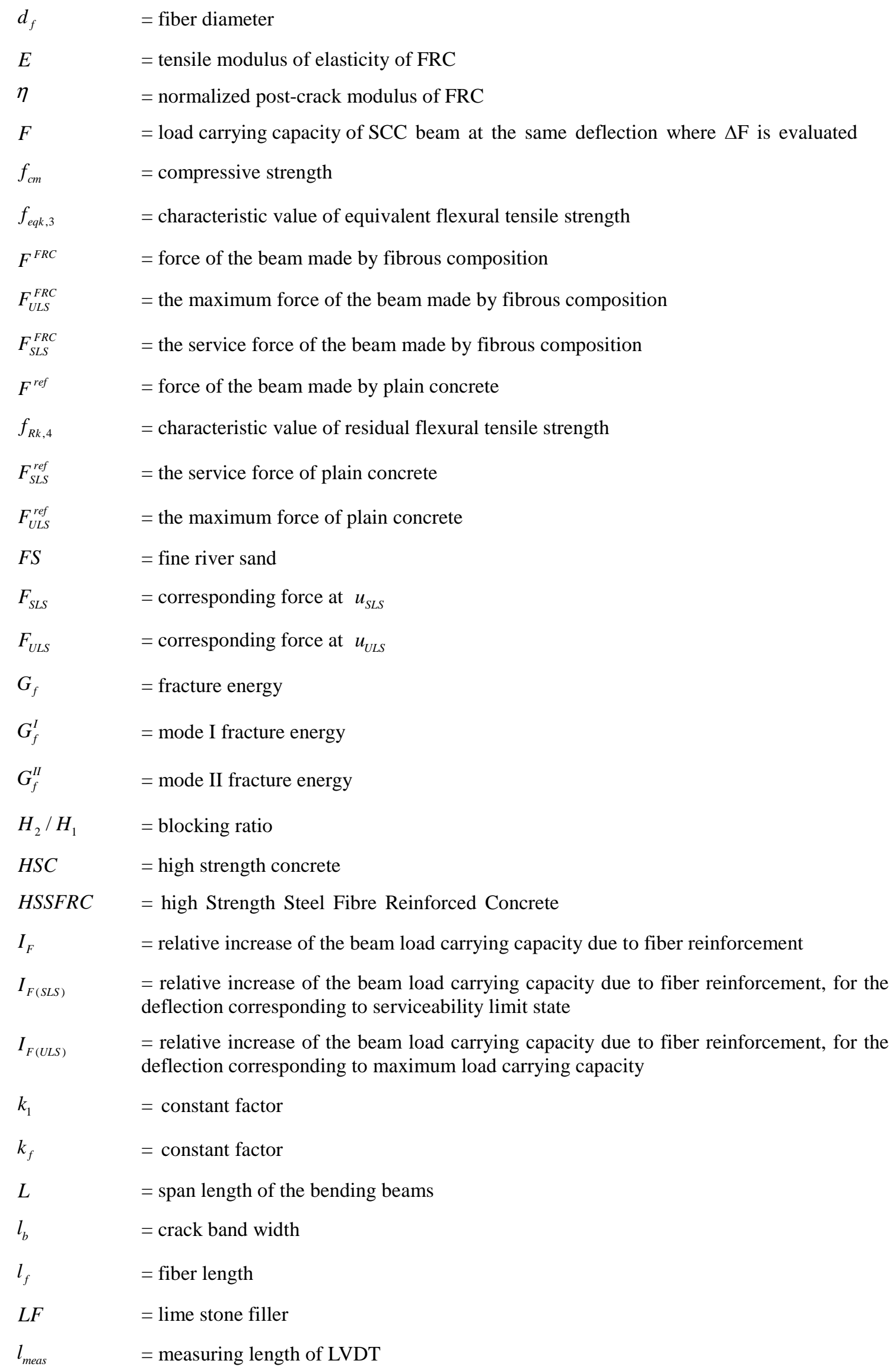




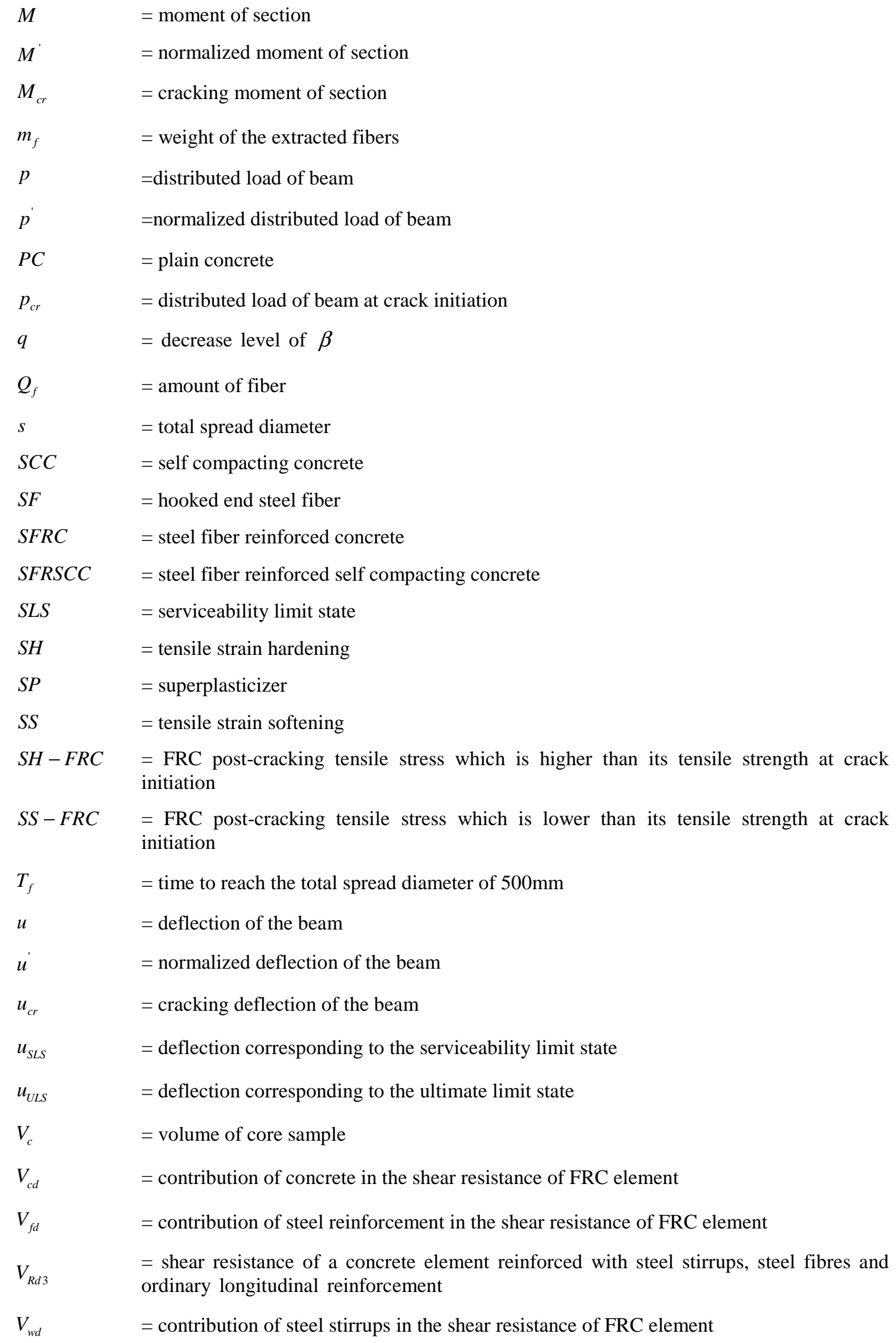




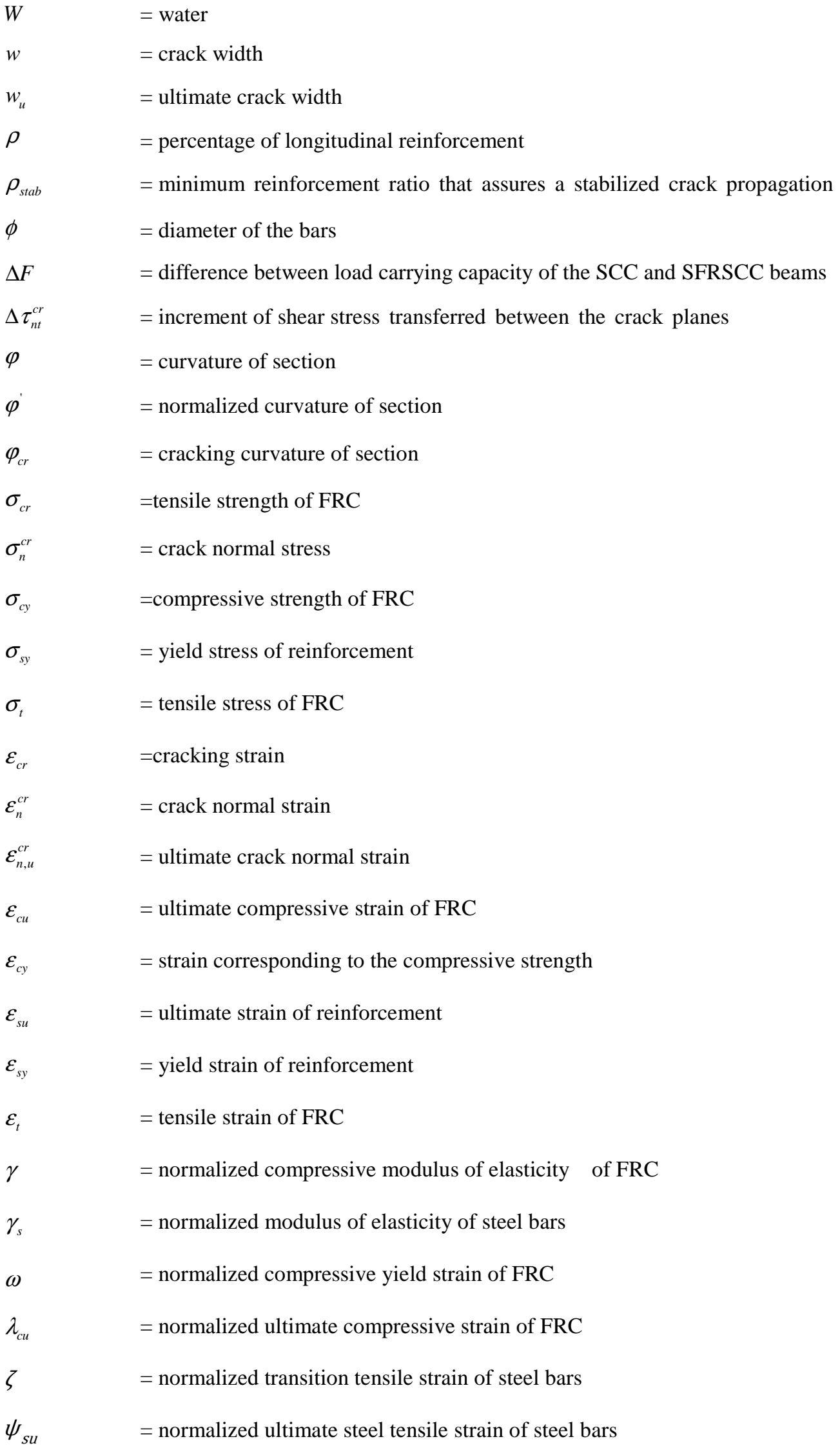




$\begin{array}{ll}\alpha_{1} & =\text { first post crack normalized stress } \\ \alpha_{2} & =\text { second post crack normalized stress } \\ \beta & =\text { shear retention factor } \\ \beta_{1} & =\text { ratio of first post cracking strain to cracking strain } \\ \beta_{2} & =\text { ratio of second post cracking strain to cracking strain } \\ \xi_{1} & =\text { ratio of first post cracking strain/crack width to ultimate strain/crack width } \\ \xi_{2} & =\text { ratio of second post cracking strain/crack width to ultimate strain/crack width } \\ \mu & =\text { normalized post crack residual strength of FRC } \\ \tau_{p}^{c r} & =\text { shear strength } \\ \tau_{f d} & =\text { design value in the shear strength due to steel fiber }\end{array}$




\section{Table captions}

Table 1 - Adopted composition (per m3 of concrete).

Table 2 - Main characteristics of the tested shallow beams.

Table 3 - Force values of the tested beams.

Table 4 - Increase provided by fibre reinforcement in terms of load carrying capacity at serviceability $\left(I_{F(S L S)}\right)$ and at ultimate $\left(I_{F(U L S)}\right)$ limit state analysis.

Table 5 - Concrete properties for the simulation of the RC beams.

Table 6 - Steel properties for the simulation of the RC beams.

Table 7 - Geometric data and values for the constitutive models for the parametric study (see Figure 9).

Table 8 - HSC mix compositions designed for the experimental program (per m3 of concrete).

Table 9 - Mechanical characterization of the tested series: compression tests.

Table 10 - Values (in $\mathrm{kN}$ ) for the FSLS and $F_{U L S}$.

Table 11 - Fibre reinforcement effectiveness indexes for serviceability $\left(I_{F(S L S)}\right)$ and ultimate $\left(I_{F(U L S)}\right)$ limit state analysis.

Table 12 - Contribution of steel fibres to the concrete shear resistance according to the RILEM TC 162-TDF formulation.

Table 13 - Values defining the tensile softening diagram, obtained from inverse analysis.

Table 14 - Values of the fracture parameters for the simulation of the HSSFRC shallow beams. 
Table 1 - Adopted composition (per $\mathrm{m}^{3}$ of concrete).

\begin{tabular}{ccccccccccccccc}
\hline \multirow{2}{*}{ Designation } & C & W & SP & LF & FS & CS & CG_1 $^{*}$ & CG_2 & SF & $s$ & $T_{f}$ & $H_{2} / H_{1}$ \\
& $(\mathrm{~kg})$ & $(\mathrm{kg})$ & $\left(\mathrm{dm}^{3}\right)$ & $(\mathrm{kg})$ & $(\mathrm{kg})$ & $(\mathrm{kg})$ & $(\mathrm{kg})$ & $(\mathrm{kg})$ & $(\mathrm{kg})$ & $(\mathrm{mm})$ & $(\mathrm{s})$ & \\
\hline SCC & 380.5 & 102.7 & 12.5 & 360.0 & 391.4 & 429.1 & 336.9 & 298.2 & 0 & 700 & 12 & 0.80 \\
\hline SFRSCC & 380.5 & 102.7 & 12.5 & 360.0 & 391.4 & 429.1 & 336.9 & 298.2 & 45.0 & 710 & 16 & 0.77 \\
\hline
\end{tabular}


Table 2 - Main characteristics of the tested shallow beams.

\begin{tabular}{|c|c|c|c|c|}
\hline Designation & $\begin{array}{c}\text { Longitudinal } \\
\text { Reinforcement } \\
\left(A_{s l}^{+}\right)\end{array}$ & $\begin{array}{l}\text { Percentage of longitudinal rei } \\
\text { nforcement }(\rho)^{*}\end{array}$ & $\begin{array}{l}\text { Fibre content } \\
\text { FC }\left(\mathrm{kg} / \mathrm{m}^{3}\right)\end{array}$ & Series \\
\hline $\begin{array}{l}\text { A1_6_0 } \\
\text { A2_6_0 }\end{array}$ & $3 \varnothing 6$ & 0.20 & 0 & \multirow{2}{*}{$\mathrm{A}$} \\
\hline $\begin{array}{l}\text { A1_6_45 } \\
\text { A2_6_45 }\end{array}$ & $3 \varnothing 6$ & 0.20 & 45 & \\
\hline $\begin{array}{l}\text { B1_8_0 } \\
\text { B2_8_0 }\end{array}$ & $3 \varnothing 8$ & 0.36 & 0 & \multirow{2}{*}{ B } \\
\hline $\begin{array}{l}\text { B1_8_45 } \\
\text { B2_8_45 }\end{array}$ & $3 \varnothing 8$ & 0.36 & 45 & \\
\hline $\begin{array}{l}\mathrm{C} 1 \_10 \_0 \\
\mathrm{C} 2 \_10 \_0\end{array}$ & $3 \varnothing 10$ & 0.56 & 0 & \multirow{2}{*}{$\mathrm{C}$} \\
\hline $\begin{array}{l}\mathrm{C} 1 \_10 \_45 \\
\mathrm{C} 2 \_10 \_45\end{array}$ & $3 \varnothing 10$ & 0.56 & 45 & \\
\hline
\end{tabular}


Table 3 - Force values of the tested beams.

\begin{tabular}{|c|c|c|c|c|c|c|c|c|c|}
\hline \multirow[b]{2}{*}{$\cdot \frac{\mathscr{\omega}}{\tilde{\omega}}$} & \multirow[b]{2}{*}{$\rho$} & \multicolumn{3}{|c|}{$F_{S L S}(\mathrm{kN})$} & \multicolumn{3}{|c|}{$F_{U L S}(\mathrm{kN})$} & \multirow[b]{2}{*}{$\frac{F_{S L S}^{r e f}}{F_{U L S}^{r e f}}$} & \multirow[b]{2}{*}{$\frac{F_{S L S}^{F R C}}{F_{U L S}^{F R C}}$} \\
\hline & & $F^{r e f}$ & $F^{F R C}$ & $\frac{F^{F R C}}{F^{r e f}}$ & $\begin{array}{c}F^{r e f} \\
{[\mathrm{FC}=0]}\end{array}$ & $\begin{array}{c}F^{F R C} \\
{[\mathrm{FC}=45]}\end{array}$ & $\frac{F^{F R C}}{F^{r e f}}$ & & \\
\hline A & 0.20 & 27.68 & 49.03 & 1.77 & 29.19 & 50.76 & 1.74 & 0.95 & 0.97 \\
\hline B & 0.36 & 42.46 & 64.45 & 1.52 & 55.42 & 78.96 & 1.42 & 0.77 & 0.82 \\
\hline $\mathrm{C}$ & 0.56 & 55.53 & 71.60 & 1.29 & 83.53 & 102.59 & 1.23 & 0.66 & 0.70 \\
\hline
\end{tabular}

FC: fibre content in $\mathrm{kg} / \mathrm{m}^{3}$ 
Table 4 - Increase provided by fibre reinforcement in terms of load carrying capacity at serviceability $\left(I_{F(S L S)}\right)$ and at ultimate $\left(I_{F(U L S)}\right)$ limit state analysis.

\begin{tabular}{ccc}
\hline Designation & $I_{F(S L S)}(\%)$ & $I_{F(U L S)}(\%)$ \\
\hline L_6 & 77.13 & 73.90 \\
L_8 & 51.79 & 42.48 \\
L_10 & 28.94 & 22.82 \\
\hline
\end{tabular}

FC: fibre content in $\mathrm{kg} / \mathrm{m}^{3}$ 
Table 5 - Concrete properties for the simulation of the RC beams.

\begin{tabular}{|c|c|c|c|c|c|c|c|c|}
\hline \multirow[b]{2}{*}{ Panel } & \multicolumn{2}{|c|}{ Compression } & \multicolumn{2}{|l|}{ Tensile strength } & \multicolumn{3}{|c|}{ Tensile softening } & \multirow[b]{2}{*}{$\begin{array}{c}G_{f}{ }^{*} \\
(\mathrm{~N} / \mathrm{mm})\end{array}$} \\
\hline & $\begin{array}{c}f_{c k} \\
(\mathrm{MPa})\end{array}$ & $E(\mathrm{GPa})$ & $\sigma_{c r}(\mathrm{MPa})$ & $\beta_{1}$ & $\alpha_{1}$ & $\beta_{2}$ & $\alpha_{2}$ & \\
\hline L_6_0 & 86.34 & 40.00 & 3.00 & 2.00 & 0.20 & 4.00 & 0.10 & 0.080 \\
\hline L_8_0 & 86.34 & 40.00 & 3.00 & 2.30 & 0.45 & 6.00 & 0.42 & 0.092 \\
\hline L_10_0 & 86.34 & 40.00 & 3.00 & 2.30 & 0.45 & 6.00 & 0.41 & 0.085 \\
\hline L_6_45 & 91.22 & 45.00 & 3.50 & 5.00 & 0.65 & 40.00 & 0.45 & 3.900 \\
\hline L_8_45 & 91.22 & 45.00 & 3.50 & 5.00 & 0.65 & 80.00 & 0.57 & 3.900 \\
\hline L_10_45 & 91.22 & 45.00 & 3.50 & 5.00 & 0.65 & 60.00 & 0.43 & 3.900 \\
\hline
\end{tabular}

* To transform a stress-crack with into a stress-strain relationship a crack band width value of 45mm (almost three times the maximum aggregate size, according to Bazant e Oh recommendations) was used 
Table 6 - Steel properties for the simulation of the RC beams.

\begin{tabular}{ccccc}
\hline Diameter & $\begin{array}{c}\text { Elasticity Modulus } \\
(\mathrm{mm})\end{array}$ & $\begin{array}{c}\text { Yield stress } \\
(\mathrm{GPa})\end{array}$ & $\begin{array}{c}\text { Tensile strength } \\
(\mathrm{MPa})\end{array}$ & $\begin{array}{c}\text { Ultimate strain } \\
(\mathrm{MPa})\end{array}$ \\
\hline 6 & 200 & 514 & 605 & 1.0 \\
8 & 200 & 559 & 635 & 1.4 \\
10 & 200 & 550 & 625 & 1.2 \\
\hline
\end{tabular}


Table 7 - Geometric data and values for the constitutive models for the parametric study (see Figure 9).

\begin{tabular}{|c|c|c|c|c|c|c|c|c|c|c|c|c|c|c|}
\hline $\begin{array}{c}b^{*} \\
(\mathrm{~mm})\end{array}$ & $\begin{array}{c}d \\
*(\mathrm{~mm})\end{array}$ & $\begin{array}{l}d^{\prime} * \\
(\mathrm{~mm})\end{array}$ & $\begin{array}{l}\mathcal{E}_{c r} \\
(\%)\end{array}$ & $\begin{array}{c}E \\
(\mathrm{GPa})\end{array}$ & $\beta_{2}$ & $\beta_{1}$ & $\mu$ & $\gamma$ & $\omega$ & $\lambda_{c u}$ & $\gamma_{s}$ & $\zeta$ & $\psi_{s u}$ & $\begin{array}{c}\rho \\
(\%)\end{array}$ \\
\hline 250 & 500 & 50 & 0.01 & 30 & 150 & $\begin{array}{c}{[1.01-15]^{* *}} \\
{[5.0-20.0]^{* * *}}\end{array}$ & $\begin{array}{l}{[0.01-0.99]^{* *}} \\
{[1.02-2.98]^{* * *}}\end{array}$ & 1 & 10 & 40 & 10 & 12 & 120 & {$[0.0-0.8]$} \\
\hline
\end{tabular}

$* b:$ width of the cross section; $d:$ depth of the cross section; $d^{\prime}:$ internal arm of the longitudinal reinforcement.

** For strain softening

$* * *$ For strain hardening 
Table 8 - HSC mix compositions designed for the experimental program (per $\mathrm{m}^{3}$ of concrete).

\begin{tabular}{|c|c|c|c|c|c|c|c|c|c|}
\hline Series & $\begin{array}{c}\text { Cement } \\
(\mathrm{kg})\end{array}$ & $\begin{array}{l}\text { Water } \\
\left(\mathrm{dm}^{3}\right)\end{array}$ & $\begin{array}{l}\mathrm{SP} \\
(\mathrm{kg})\end{array}$ & $\begin{array}{l}\mathrm{LF} \\
(\mathrm{kg})\end{array}$ & $\begin{array}{c}\text { Coarse Agg. } 2 \\
(\mathrm{~kg})\end{array}$ & $\begin{array}{c}\text { Coarse Agg. } 1 \\
(\mathrm{~kg})\end{array}$ & $\begin{array}{c}\text { Fine Agg. } \\
(\mathrm{kg})\end{array}$ & $\begin{array}{c}\text { Fine Sand } \\
(\mathrm{kg})\end{array}$ & $\begin{array}{c}\text { Steel Fibres } \\
(\mathrm{kg})\end{array}$ \\
\hline $\begin{array}{c}f_{c m 50} \\
\text { NoFibres }\end{array}$ & 300.00 & 120.46 & 5.36 & 114.00 & 308.98 & 309.19 & 503.35 & 586.99 & 0.00 \\
\hline$f_{c m 50-F C 60}$ & 300.00 & 120.46 & 7.01 & 228.00 & 294.27 & 294.46 & 457.59 & 533.63 & 60.00 \\
\hline$f_{c m 50-F C 75}$ & 300.00 & 120.46 & 7.01 & 228.00 & 286.14 & 286.51 & 448.93 & 560.56 & 75.00 \\
\hline $\begin{array}{c}f_{c m 70} \\
\text { NoFibres }\end{array}$ & 400.00 & 114.00 & 7.84 & 200.00 & 303.10 & 303.30 & 471.32 & 549.63 & 0.00 \\
\hline$f_{c m 70 \_} F C 60$ & 400.00 & 114.00 & 10.65 & 342.00 & 282.50 & 282.69 & 439.29 & 512.28 & 60.00 \\
\hline$f_{c m 70 \_} F C 75$ & 400.00 & 114.00 & 10.65 & 342.00 & 266.11 & 266.45 & 417.50 & 521.32 & 75.00 \\
\hline
\end{tabular}


Table 9 - Mechanical characterization of the tested series: compression tests (average of 3 specimens)

\begin{tabular}{|c|c|c|c|}
\hline Series & $E \quad(\mathrm{GPa})$ & $f_{c m}(\mathrm{MPa})$ & Strain at compressive strength $(\%)$ \\
\hline$f_{c m 50 \_ \text {NoFibres }}$ & $36.31(8.51)$ & $41.74(2.76)$ & $0.350(0.25)$ \\
\hline$f_{c m 50-F C 60}$ & $37.05(2.90)$ & $46.58(0.78)$ & $0.415(0.11)$ \\
\hline$f_{c m 50-} F C 75$ & $39.01(0.81)$ & $48.10(0.28)$ & $0.377(0.13)$ \\
\hline$f_{c m 70 \_ \text {NoFibres }}$ & $48.41(1.44)$ & $66.38(0.45)$ & $0.310(0.10)$ \\
\hline$f_{c m 70-F C 60}$ & $45.68(0.36)$ & $65.73(3.33)$ & $0.337(0.36)$ \\
\hline$f_{c m 70-} F C 75$ & $43.75(0.97)$ & $66.08(2.06)$ & $0.343(0.24)$ \\
\hline
\end{tabular}

() Coefficient of variation 
Table 10 - Values (in $\mathrm{kN}$ ) for the FSLS and FULS.

\begin{tabular}{|c|c|c|c|c|c|c|}
\hline \multirow{3}{*}{ Series } & \multicolumn{3}{|c|}{$F_{S L S}$} & \multicolumn{3}{|c|}{$F_{U L S}$} \\
\hline & $F^{r e f}$ & $F^{F R C}$ & $F^{F R C}$ & $F^{r e f}$ & $F^{F R C}$ & $F^{F R C}$ \\
\hline & {$[\mathrm{FC}=0]$} & {$[\mathrm{FC}=60]$} & {$[\mathrm{FC}=75]$} & {$[\mathrm{FC}=0]$} & {$[\mathrm{FC}=60]$} & {$[\mathrm{FC}=75]$} \\
\hline$f_{c m 50}$ & 97.35 & 146.06 & 154.83 & 97.66 & 187.50 & 212.73 \\
\hline$f_{c m 70}$ & 112.10 & 160.29 & 192.36 & 125.23 & 225.82 & 252.90 \\
\hline
\end{tabular}

FC: fibre content in $\mathrm{kg} / \mathrm{m}^{3}$ 
Table 11 - Fibre reinforcement effectiveness indexes for serviceability (IF(SLS)) and ultimate (IF(ULS)) limit state analysis.

\begin{tabular}{ccccc}
\hline \multirow{2}{*}{ Series } & \multicolumn{2}{c}{$I_{F(S L S)}(\%)$} & $I_{F(\text { ULS })}(\%)$ \\
\cline { 2 - 5 } & {$[\mathrm{FC}=60]$} & {$[\mathrm{FC}=75]$} & {$[\mathrm{FC}=60]$} & {$[\mathrm{FC}=75]$} \\
\hline$f_{c m 50}$ & 50.04 & 59.05 & 91.99 & 117.84 \\
$f_{c m 70}$ & 42.98 & 71.59 & 80.33 & 101.96 \\
\hline
\end{tabular}

FC: fibre content in $\mathrm{kg} / \mathrm{m}^{3}$ 
Table 12 - Contribution of steel fibres to the concrete shear resistance according to the RILEM TC 162-TDF

\begin{tabular}{|c|c|c|c|c|c|c|c|c|c|c|c|}
\hline Series & $\begin{array}{c}f_{c m} \\
(\mathrm{MPa})\end{array}$ & $\begin{array}{c}f_{c k} \\
(\mathrm{MPa})\end{array}$ & $\begin{array}{c}V_{c d} \\
(\mathrm{kN})\end{array}$ & $\begin{array}{l}\tau_{f d, 1}(1) \\
(\mathrm{MPa})\end{array}$ & $\begin{array}{c}\tau_{f d, 2}(2) \\
(\mathrm{MPa})\end{array}$ & $\begin{array}{l}V_{f d}(1) \\
(\mathrm{kN})\end{array}$ & $\begin{array}{l}V_{f d}(2) \\
(\mathrm{kN})\end{array}$ & $\begin{array}{c}V_{R d}^{(1)} \\
(\mathrm{kN})\end{array}$ & $\begin{array}{c}V_{R d}(2) \\
(\mathrm{kN})\end{array}$ & $\mathrm{SF}, 1^{(3)}$ & $\mathrm{SF}, 2^{(3)}$ \\
\hline $\begin{array}{c}f_{\text {cm50 }} \\
\text { NoFibres }\end{array}$ & 41.74 & 33.74 & 30.36 & - & - & - & - & 30.36 & - & 1.61 & - \\
\hline$f_{c m 50 \_} F C 60$ & 46.58 & 38.58 & 31.65 & 0.97 & 0.91 & 18.23 & 17.15 & 49.88 & 48.80 & 1.88 & 1.92 \\
\hline$f_{c m 50-F C 75}$ & 48.10 & 40.10 & 32.16 & 0.87 & 0.82 & 16.29 & 15.34 & 48.45 & 47.50 & 2.20 & 2.24 \\
\hline $\begin{array}{c}f_{c m 70} \\
\text { NoFibres }\end{array}$ & 66.39 & 58.39 & 36.45 & - & - & - & - & 36.45 & - & 1.72 & - \\
\hline$f_{c m 70-F C 60}$ & 65.73 & 57.73 & 36.31 & 1.13 & 0.82 & 21.15 & 15.45 & 57.46 & 51.76 & 1.95 & 2.17 \\
\hline$f_{c m 70 \_} F C 75$ & 66.08 & 58.08 & 36.38 & 0.90 & 0.49 & 16.95 & 9.19 & 53.33 & 45.57 & 2.36 & 2.72 \\
\hline
\end{tabular}

(1)Considering $\tau_{f d}=0.12 f_{e q, 3}\left[\mathrm{~N} / \mathrm{mm}^{2}\right]$; (2) Considering $\tau_{f d}=0.12 f_{R, 4}\left[\mathrm{~N} / \mathrm{mm}^{2}\right]$; (3) Ratio between $V_{\exp }$ and $V_{R d}{ }^{(1)}$ (or $\left.V_{R d}{ }^{(2)}\right)$. 
Table 13 - Values defining the tensile softening diagram, obtained from inverse analysis.

\begin{tabular}{|c|c|c|c|c|c|c|c|}
\hline \multirow[b]{2}{*}{ Series } & \multicolumn{7}{|c|}{ Tensile softening law } \\
\hline & $\begin{array}{c}E \\
\left(\mathrm{~N} / \mathrm{mm}^{2}\right)\end{array}$ & $\begin{array}{c}\sigma_{n 1}^{c r} \\
\left(\mathrm{~N} / \mathrm{mm}^{2}\right)\end{array}$ & $\xi_{1}$ & $\alpha_{1}$ & $\xi_{2}$ & $\alpha_{2}$ & $\begin{array}{c}G_{f}^{I} \\
(\mathrm{~N} / \mathrm{mm})\end{array}$ \\
\hline$f_{c m 50 \_} F C 60$ & 37045 & 1.90 & 0.014 & 0.995 & 0.035 & 1.350 & 3.200 \\
\hline$f_{c m 50} F C 75$ & 39014 & 3.50 & 0.012 & 0.995 & 0.044 & 1.200 & 5.140 \\
\hline
\end{tabular}

Note: the values of $G_{f}$ correspond to the area inside the tri-linear stress-crack opening diagram 
Table 14 - Values of the fracture parameters for the simulation of the HSSFRC shallow beams.

\begin{tabular}{ccccccccccc}
\hline & \multicolumn{1}{c}{} & \multicolumn{4}{c}{$\begin{array}{c}\text { Trilinear tension } \\
\text { softening diagram }\end{array}$} & & \multicolumn{3}{c}{$\begin{array}{c}\text { Softening crack shear } \\
\text { stress-strain diagram }\end{array}$} \\
\cline { 2 - 10 } & $\begin{array}{c}E \\
\left(\mathrm{~N} / \mathrm{mm}^{2}\right)\end{array}$ & $\begin{array}{c}\sigma_{n 1}^{c r} \\
\left(\mathrm{~N} / \mathrm{mm}^{2}\right)\end{array}$ & $\xi_{1}$ & $\alpha_{1}$ & $\xi_{2}$ & $\alpha_{2}$ & $G_{f}^{I}$ & $\begin{array}{c}\tau_{p}^{c r} \\
(\mathrm{~N} / \mathrm{mm})\end{array}$ & $G_{f}^{I I}$ \\
$\left(\mathrm{~N} / \mathrm{mm}^{2}\right)$ & $\beta$ \\
\hline $\begin{array}{l}f_{c m 50} \\
F C 60\end{array}$ & 37045 & 1.90 & 0.002 & 0.950 & 0.035 & 1.350 & 3.200 & 3.40 & 5.20 & 0.5 \\
\hline $\begin{array}{l}f_{c m 50} \\
F C 75\end{array}$ & 39014 & 3.50 & 0.001 & 0.950 & 0.044 & 1.200 & 5.140 & 3.00 & 3.10 & 0.5 \\
\hline
\end{tabular}

Threshold angle $=30^{\circ}$, Poisson's coefficient $=0.2 ; p=2$ was assumed to define $\beta$ in the simulations based on the concept of shear retention factor 


\section{Figure captions}

Fig. 1 - Geometry, support and load conditions of the tested shallow beams, including the monitoring system [mm].

Fig. 2 - Load-central deflection curves of series L_6.

Fig. 3 - Load-central deflection curves of series L_8.

Fig. 4 - Load-central deflection curves of series L_10.

Fig. 5 - Relationship between the midspan deflection and the relative increment of the beam load carrying capacity for all series.

Fig. 6 - Stress-strain diagram used in the numerical strategy.

Fig. 7 - Idealized stress-strain response of FRC: (a) tensile behaviour, (b) compressive behaviour (based on Soranakom and Mobasher 2008); and (c) idealized stress-strain diagram for steel bars.

Fig. 8 - The effect of $\beta_{1}$ parameter of SS-FRC in terms of normalized increase of: (a) flexural, and (b) load carrying capacity $\left(\Delta M=M_{\beta_{1}=15}-M_{\min }, M_{\min }=M_{\beta_{1}=1.01}, \Delta p=p_{\beta_{1}=15}-p_{\min }, p_{\min }=p_{\beta_{1}=1.01}\right)$.

Fig. 9 - The effect of $\mu$ parameter of SS-FRC in terms of normalized increase of: (a) flexural, and (b) load carrying capacity ( $\Delta M=M_{\mu=0.99}-M_{\min }, M_{\min }=M_{\mu=0.01}, \Delta p=p_{\mu=0.99}-p_{\min }, p_{\min }=p_{\mu=0.01}$.

Fig. 10 - The effect of $\beta_{1}$ parameter of SH-FRC in terms of normalized increase of: (a) flexural, and (b) load carrying capacity $\left(\Delta M=M_{\beta_{1}=5}-M_{\text {min }}, M_{\min }=M_{\beta_{1}=20}, \Delta p=p_{\beta_{1}=5}-p_{\min }, p_{\min }=p_{\beta_{1}=20}\right)$.

Fig. 11 - The effect of $\mu$ parameter of SH-FRC in terms of normalized increase of: (a) flexural, and (b) load carrying capacity $\left(\Delta M=M_{\mu=2.98}-M_{\min }, M_{\min }=M_{\mu=1.02}, \Delta p=p_{\mu=2.98}-p_{\min }, p_{\min }=p_{\mu=1.02}\right)$.

Fig. 12 - Ordinary reinforcement: a) transversal view; b) longitudinal view.

Fig. 13 - Load-displacement curves of the bending tests with prismatic specimens of a) $f_{c m 50}$ and b) $f_{c m 70}$ series.

Fig. 14 - Load-displacement curves for the a) $f_{c m 50}$ and b) $f_{c m 70}$ series.

Fig. 15 - Crack pattern in $f_{c m 50}$ series: a) without fibres, b) with $60 \mathrm{~kg} / \mathrm{m}^{3}$ and c) with $75 \mathrm{~kg} / \mathrm{m}^{3}$ of fibres.

Fig. 16 - Tri-linear normal stress - normal strain diagram to simulate the fracture mode I crack propagation.

Fig. 17 - Bi-linear shear stress-shear strain diagram to simulate the fracture mode II crack sliding.

Fig. 18 - Stress-crack opening diagram.

Fig. 19 - Finite element mesh adopted in the inverse analysis.

Fig. 20 - Force-deflection curves of the nothced beam bending tests: comparison between experimental and numerical results.

Fig. 21 - Relationship between the load and the midspan deflection for the distinct numerical simulations.

of the RC beams ( $\left.f_{c m}=50 \mathrm{MPa}\right)$. 

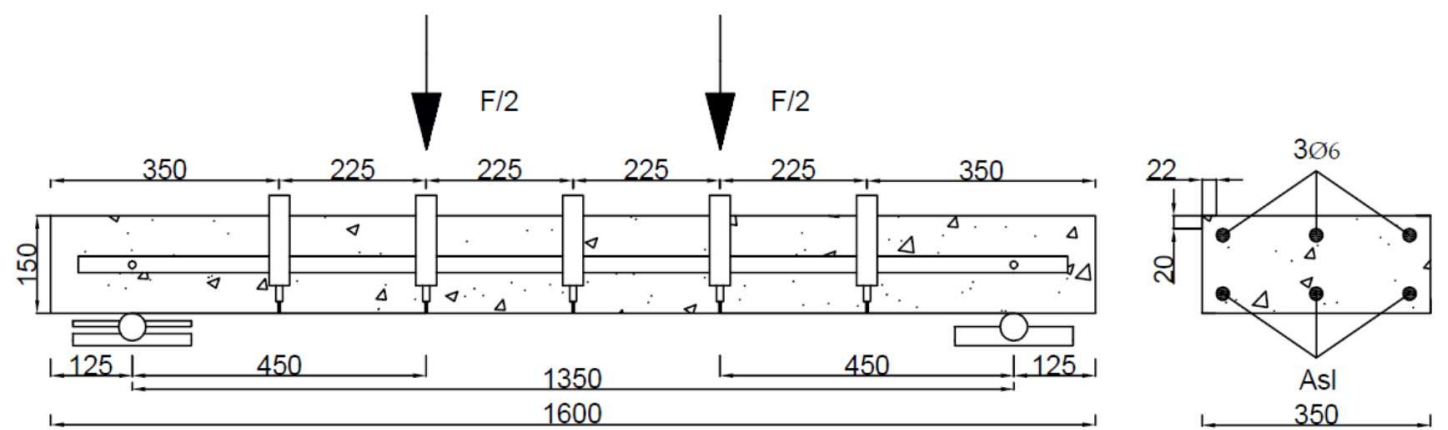

Fig. 1 - Geometry, support and load conditions of the tested shallow beams, including the monitoring system $[\mathrm{mm}]$. 


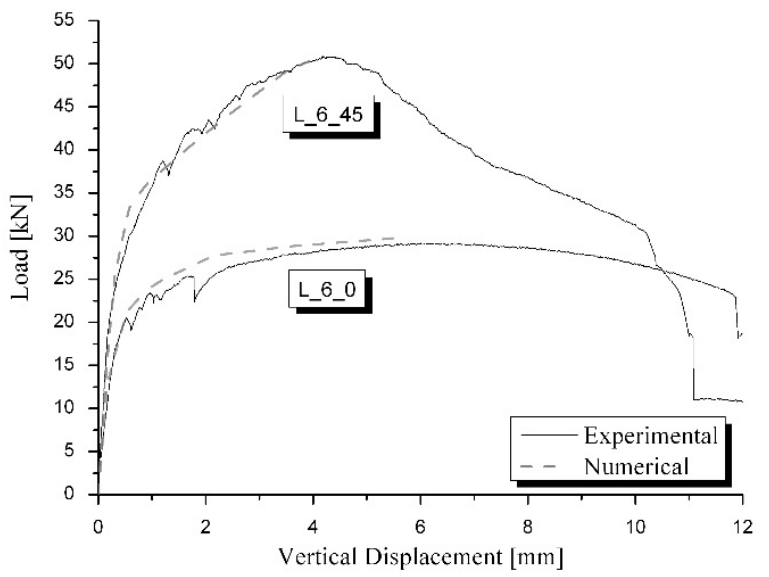

Fig. 2 - Load-central deflection curves of series L_6. 


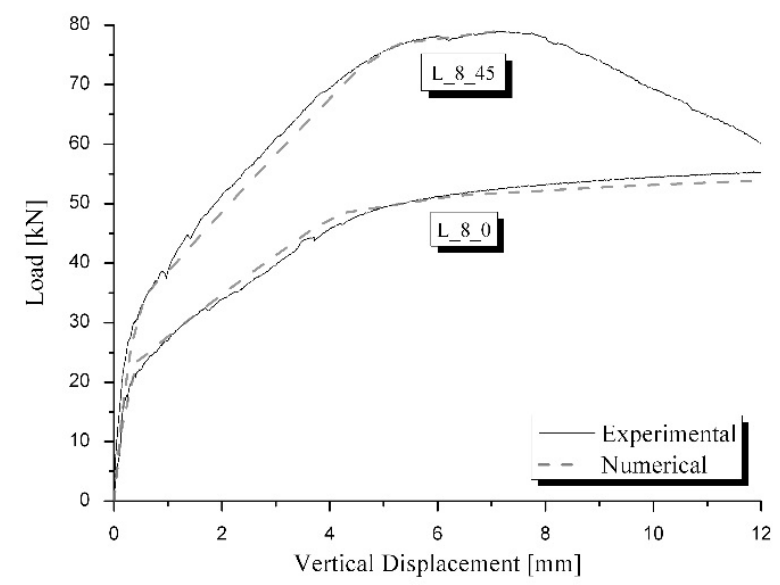

Fig. 3 - Load-central deflection curves of series L_8. 


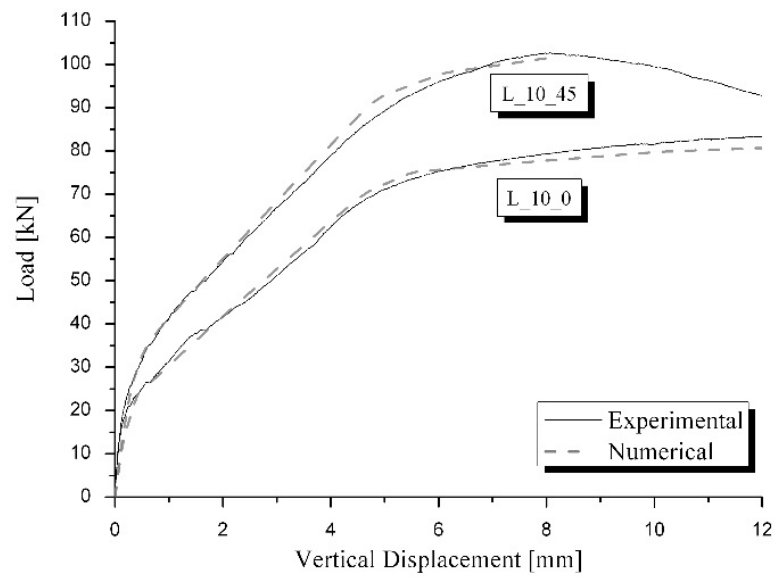

Fig. 4 - Load-central deflection curves of series L_10. 


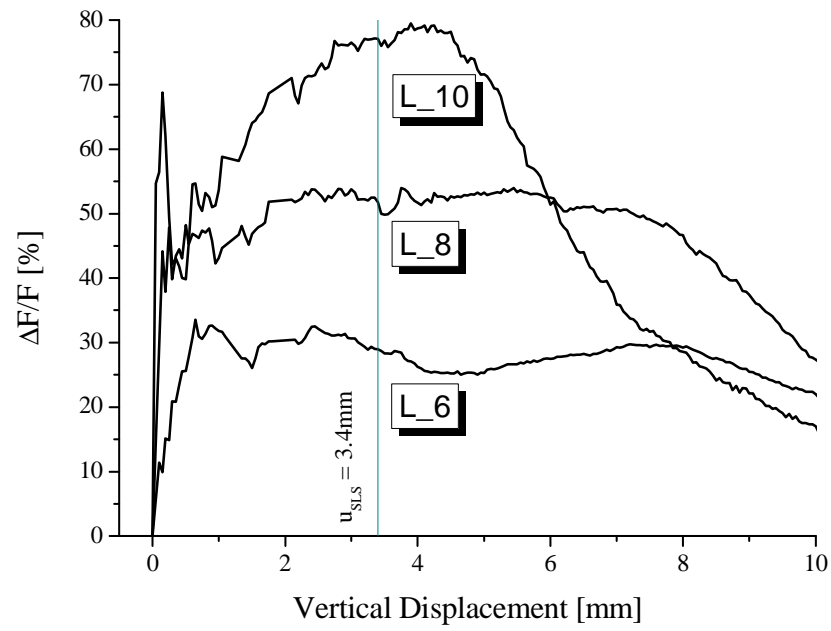

Fig. 5 - Relationship between the midspan deflection and the relative increment of the beam load carrying capacity for all series. 


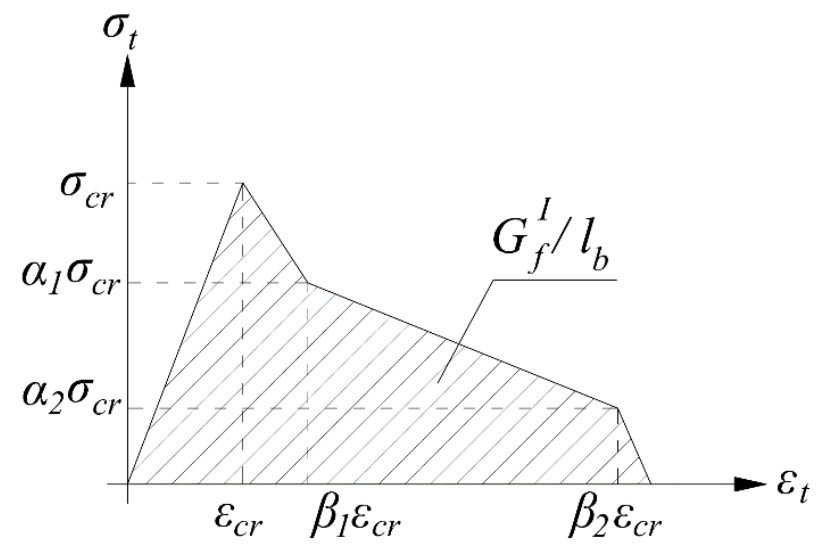

Fig. 6 - Stress-strain diagram used in the numerical strategy. 


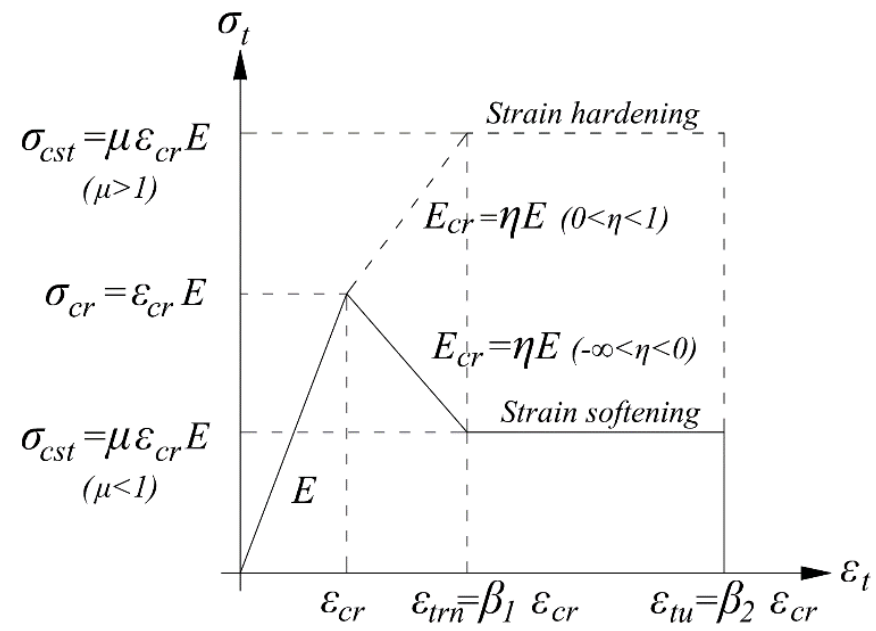

Fig. 7 - Idealized stress-strain response of FRC: (a) tensile behaviour (based on Soranakom and Mobasher 2008). 


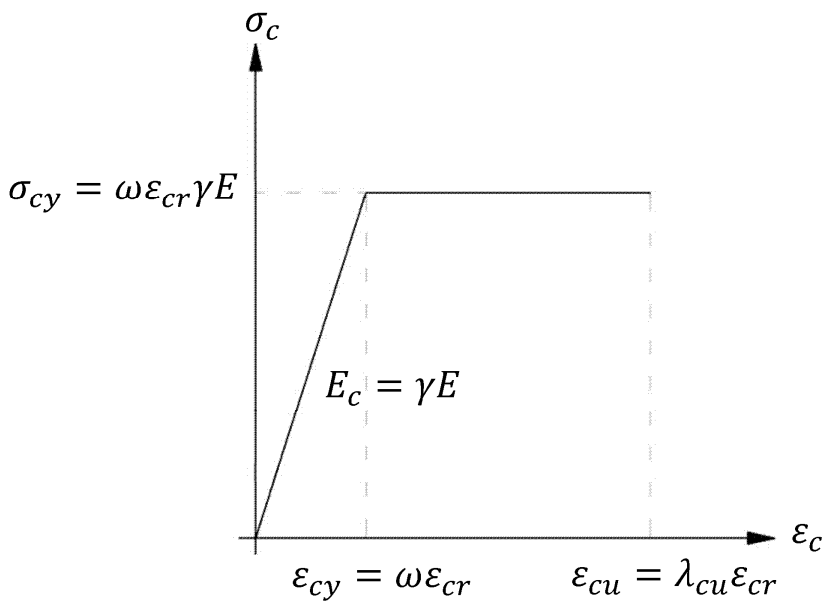

Figure 7 - Idealized stress-strain response of FRC: (b) compressive behaviour (based on Soranakom and Mobasher 2008). 


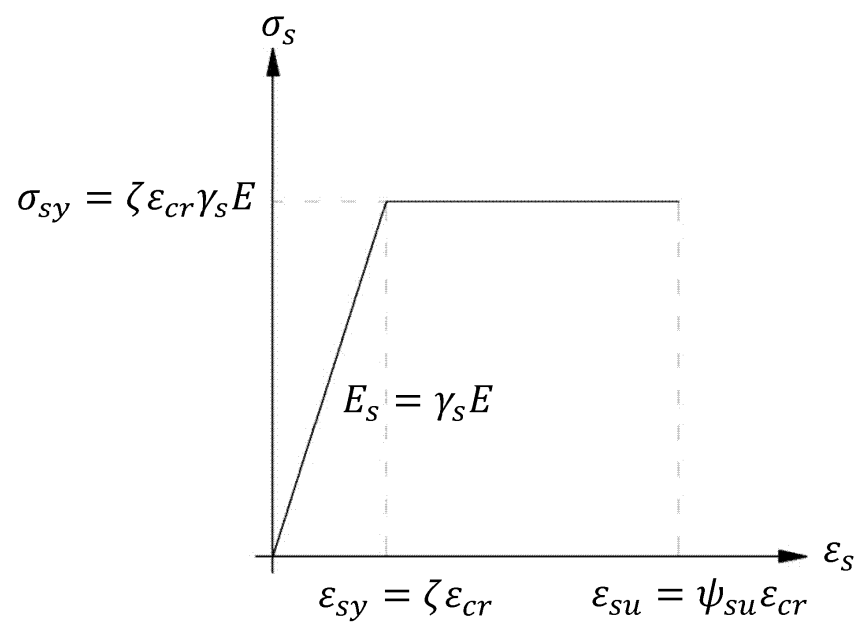

Figure 7 - Idealized stress-strain response of FRC: (c) idealized stress-strain diagram for steel bars. 


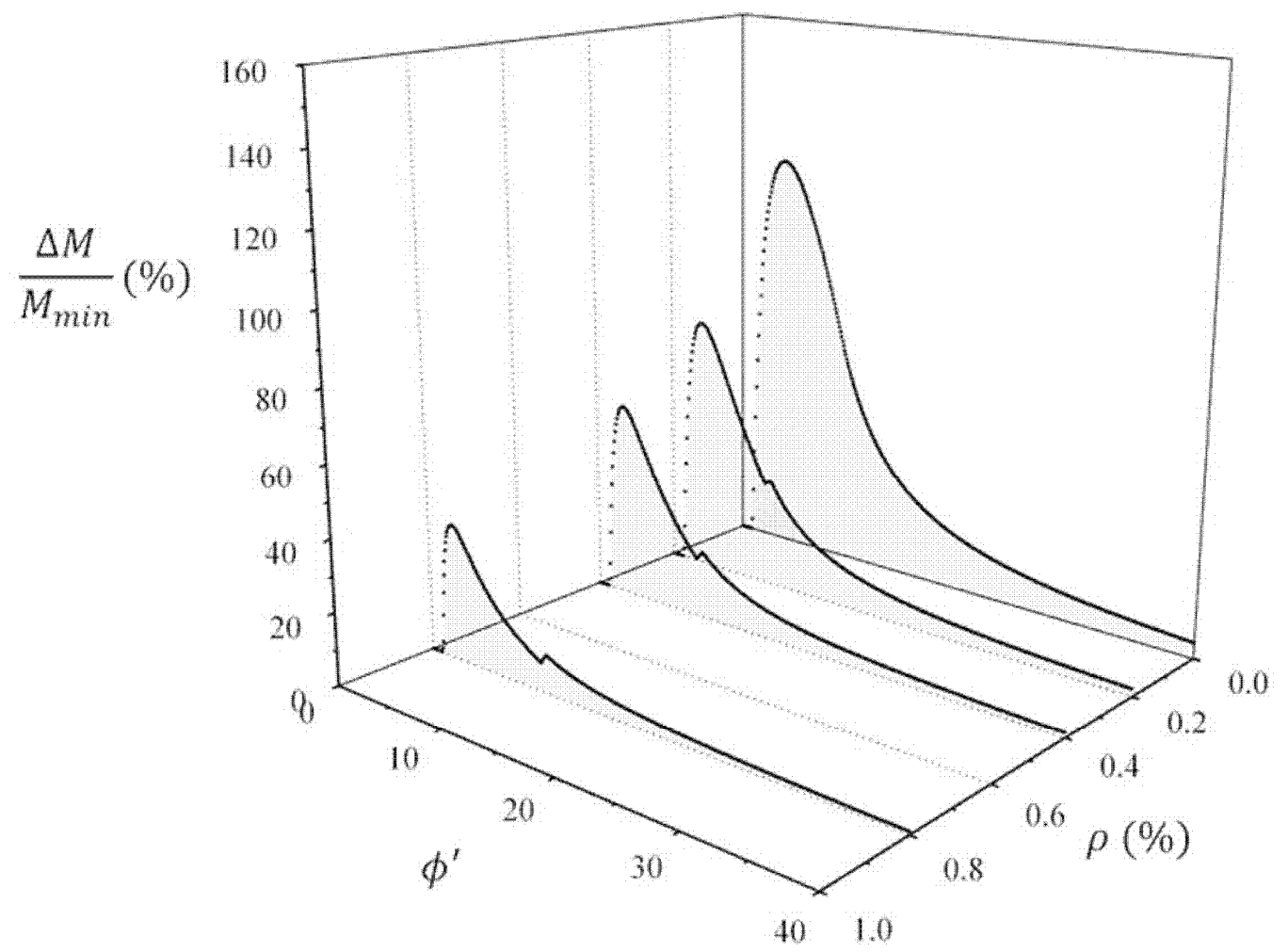

Fig. 8 - The effect of $\beta_{1}$ parameter of SS-FRC in terms of normalized increase of: (a) flexural $\left(\Delta M=M_{\beta_{1}=15}-M_{\text {min }}, \quad M_{\text {min }}=M_{\beta_{1}=1.01}\right)$. 


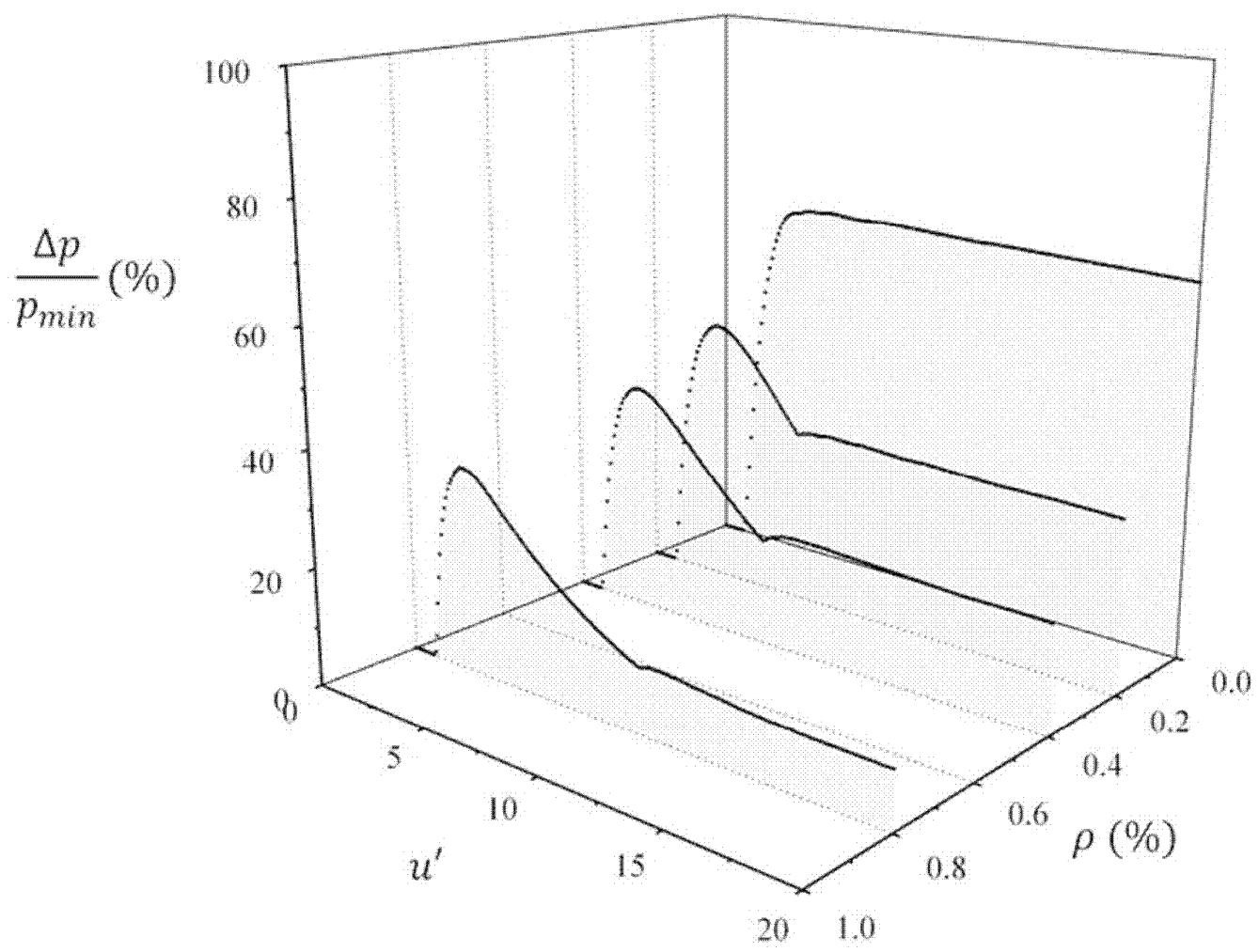

Fig. 8 - The effect of $\beta_{1}$ parameter of SS-FRC in terms of normalized increase of: (b) load carrying capacity $\left(\Delta p=p_{\beta_{1}=15}-p_{\min }, p_{\min }=p_{\beta_{1}=1.01}\right)$. 


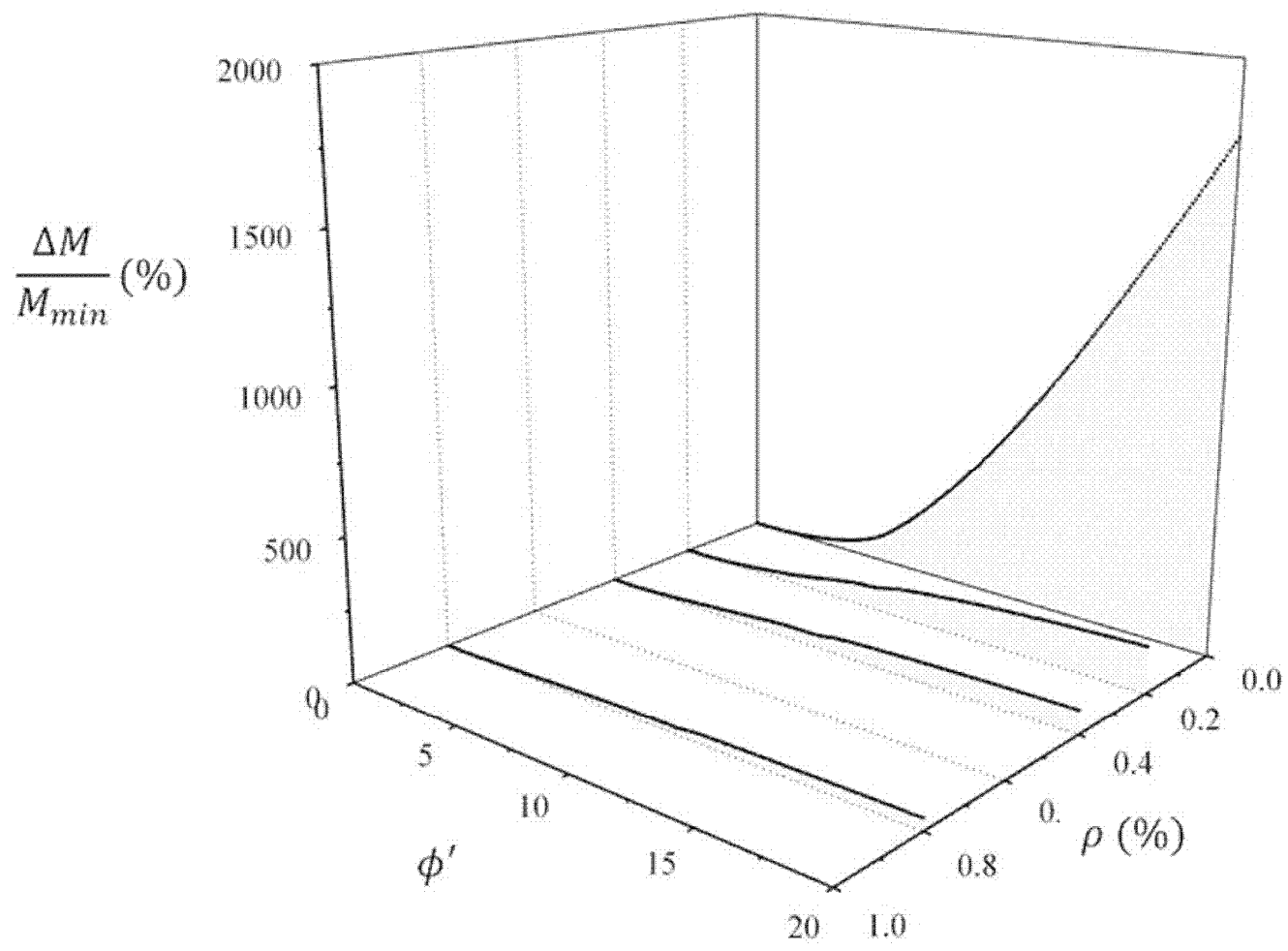

Fig. 9 - The effect of $\mu$ parameter of SS-FRC in terms of normalized increase of: (a) flexural $\left(\Delta M=M_{\mu=0.99}-M_{\min }, \quad M_{\min }=M_{\mu=0.01}\right)$ 


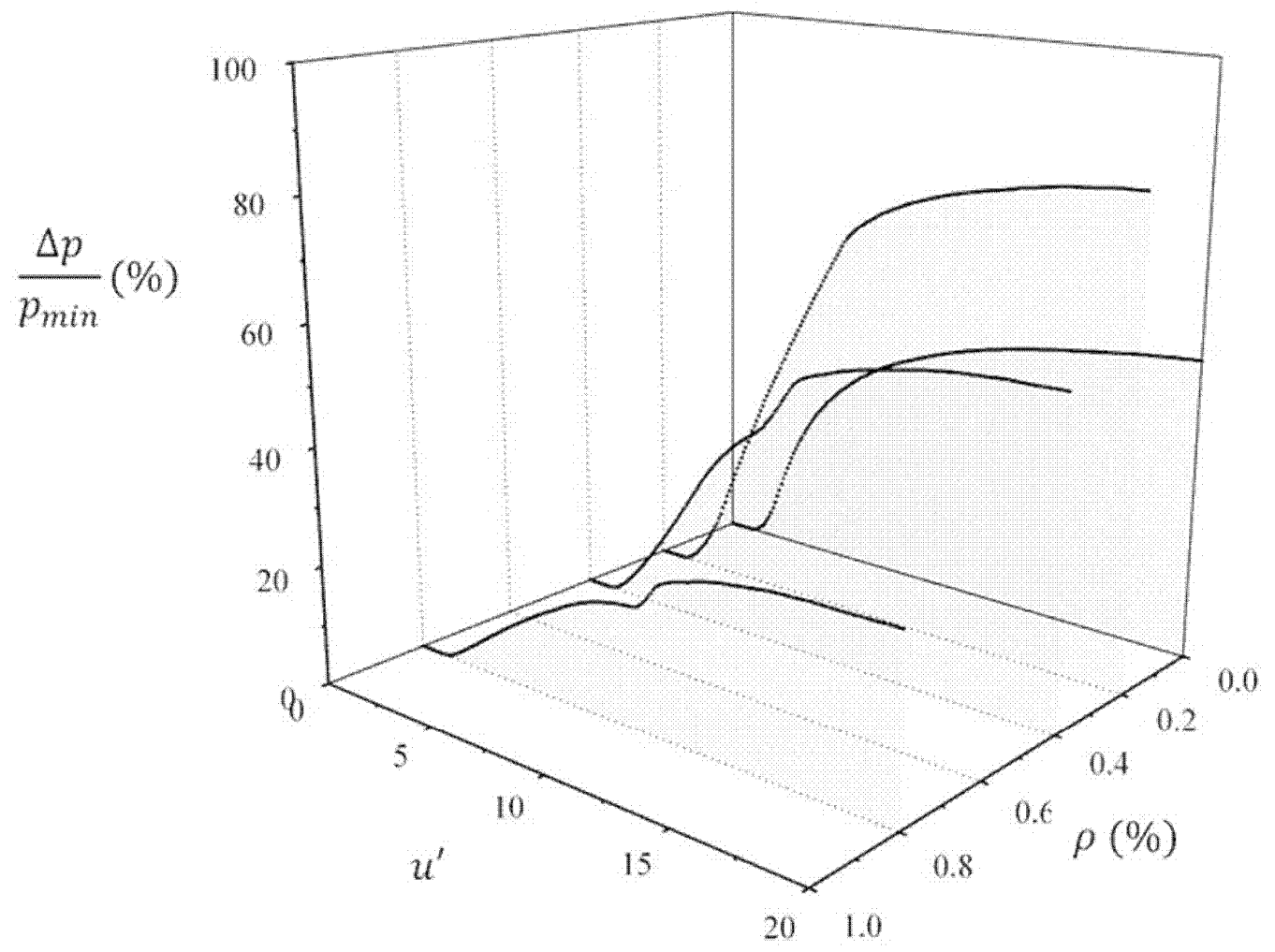

Fig. 9 - The effect of $\mu$ parameter of SS-FRC in terms of normalized increase of: (b) load carrying capacity $\left(\Delta p=p_{\mu=0.99}-p_{\text {min }}, p_{\min }=p_{\mu=0.01}\right)$ 


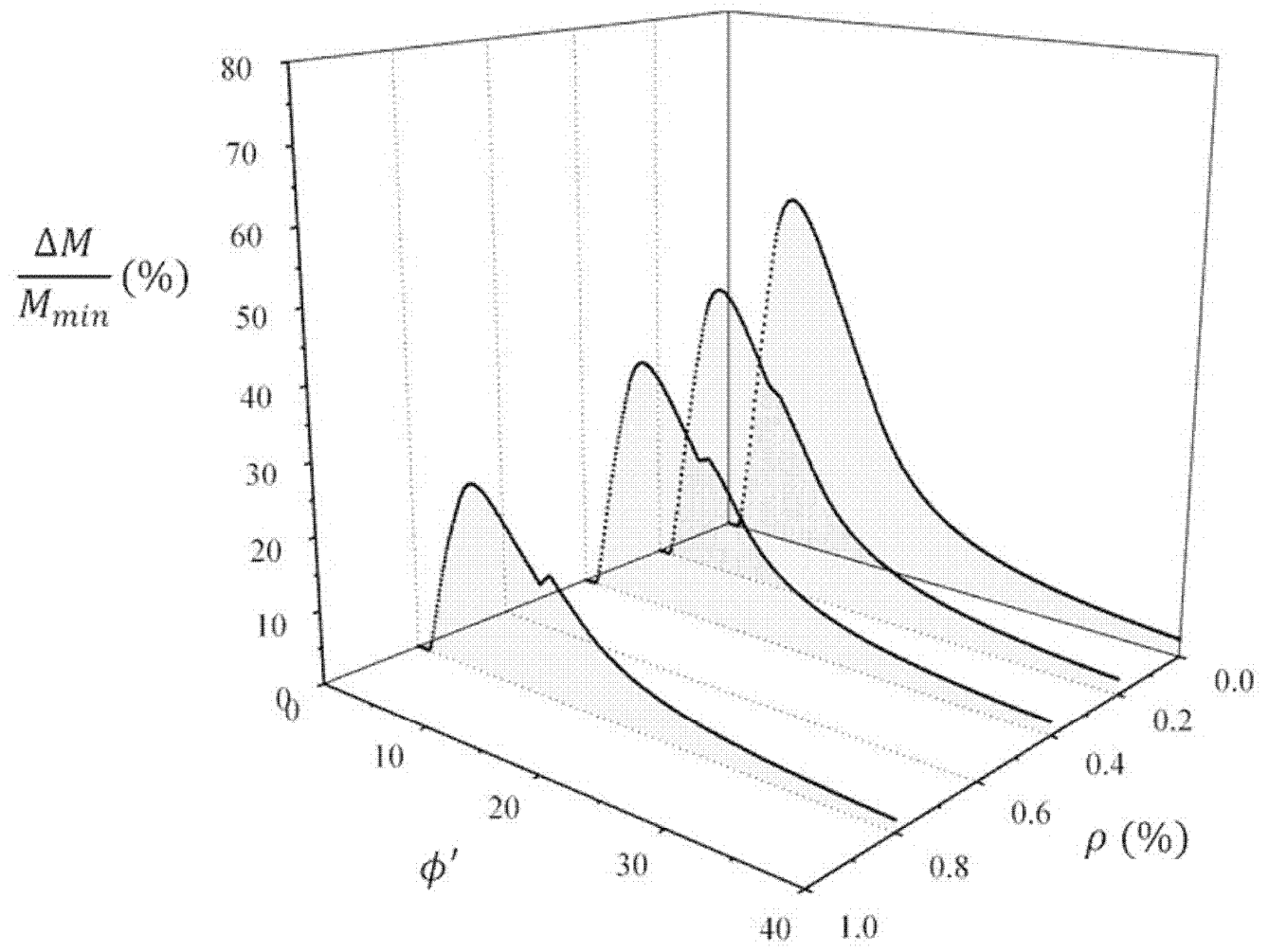

Fig. 10 - The effect of $\beta_{1}$ parameter of SH-FRC in terms of normalized increase of: (a) flexural $\left(\Delta M=M_{\beta_{1}=5}-M_{\min }, M_{\min }=M_{\beta_{1}=20}\right)$. 


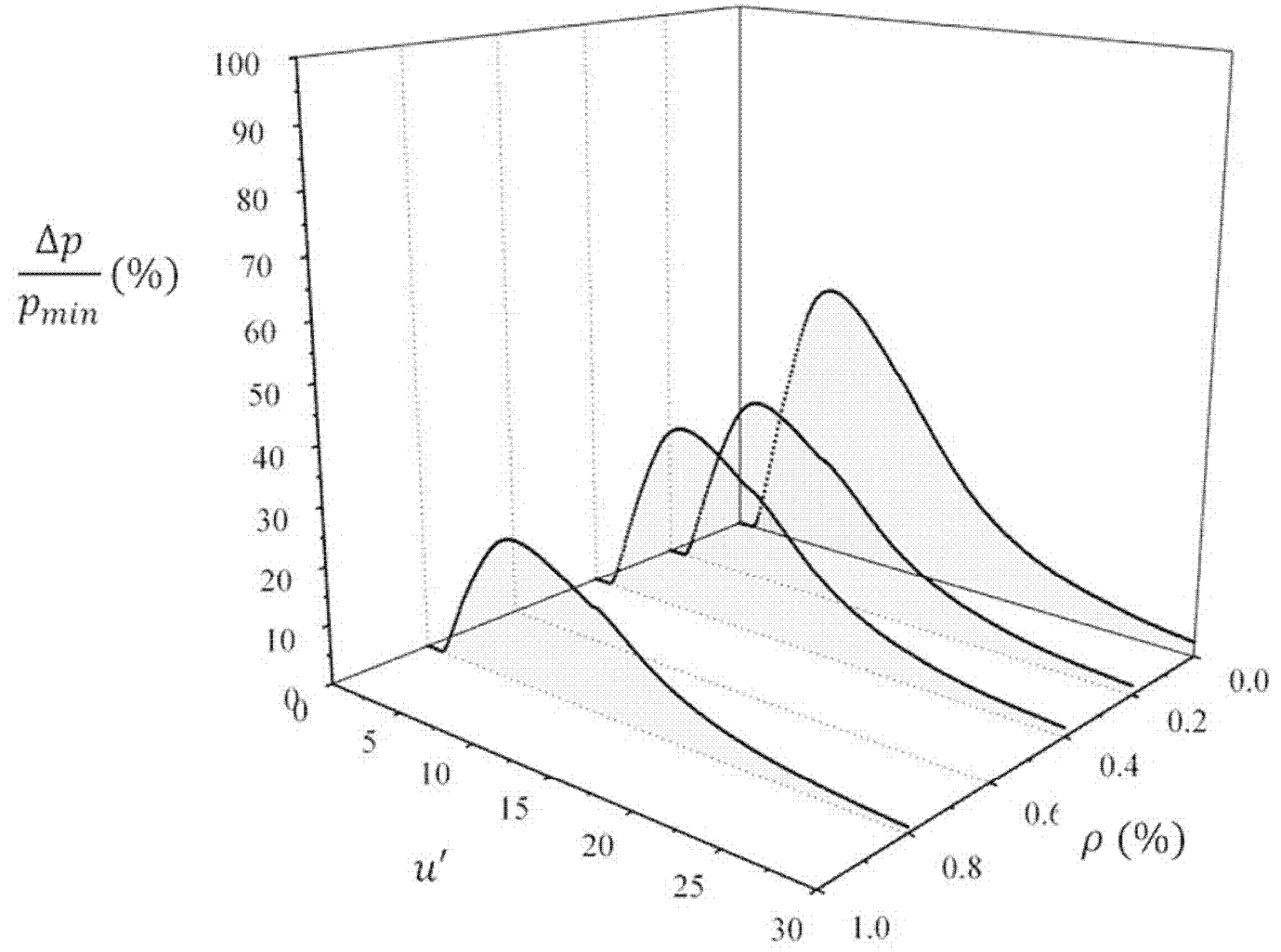

Fig. 10 - The effect of $\beta_{1}$ parameter of SH-FRC in terms of normalized increase of: (b) load carrying capacity $\left(\Delta p=p_{\beta_{1}=5}-p_{\text {min }}, p_{\text {min }}=p_{\beta_{1}=20}\right)$. 


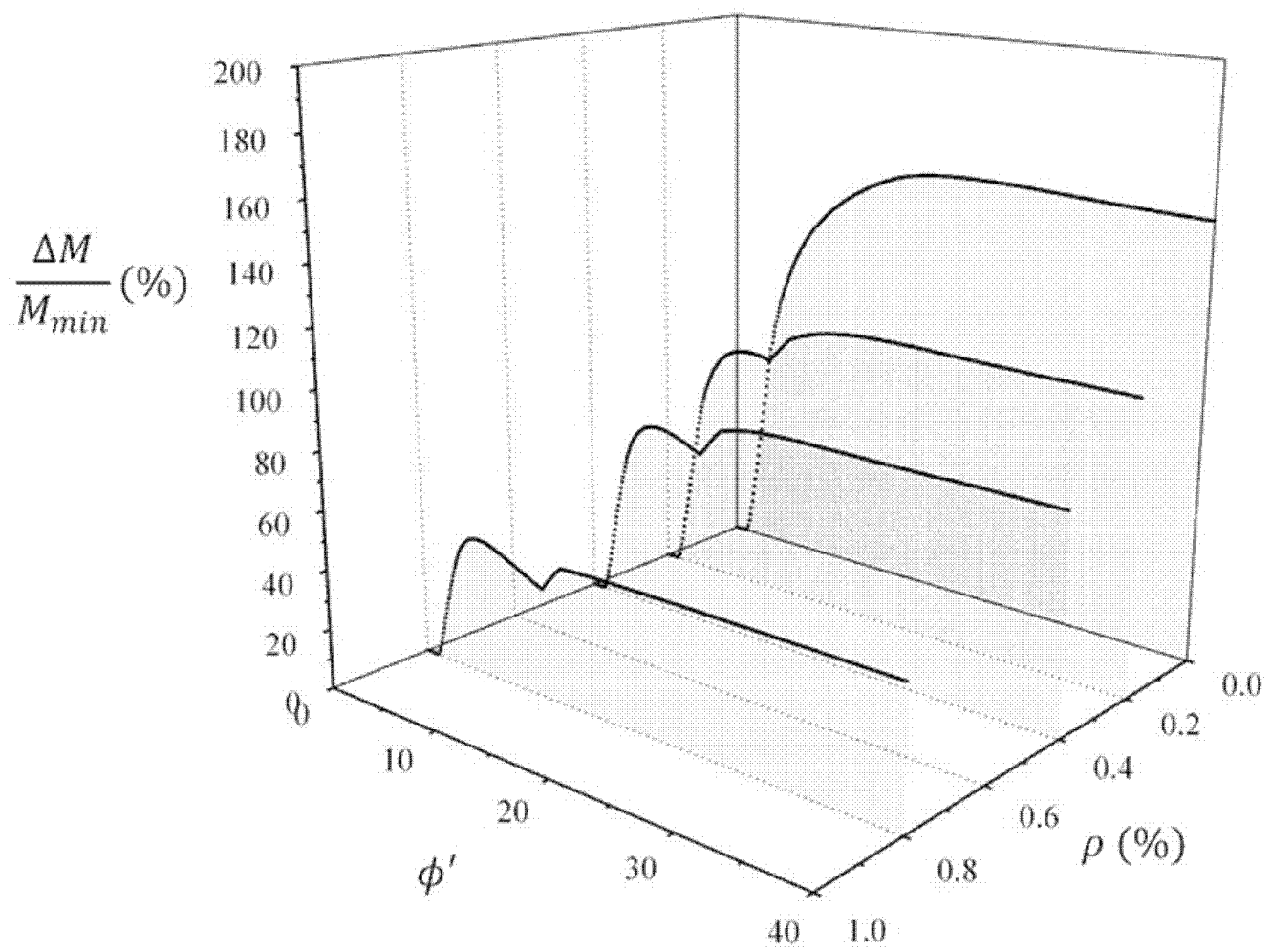

Fig. 11 - The effect of $\mu$ parameter of SH-FRC in terms of normalized increase of: (a) flexural $\left(\Delta M=M_{\mu=2.98}-M_{\text {min }}, \quad M_{\text {min }}=M_{\mu=1.02}\right)$. 


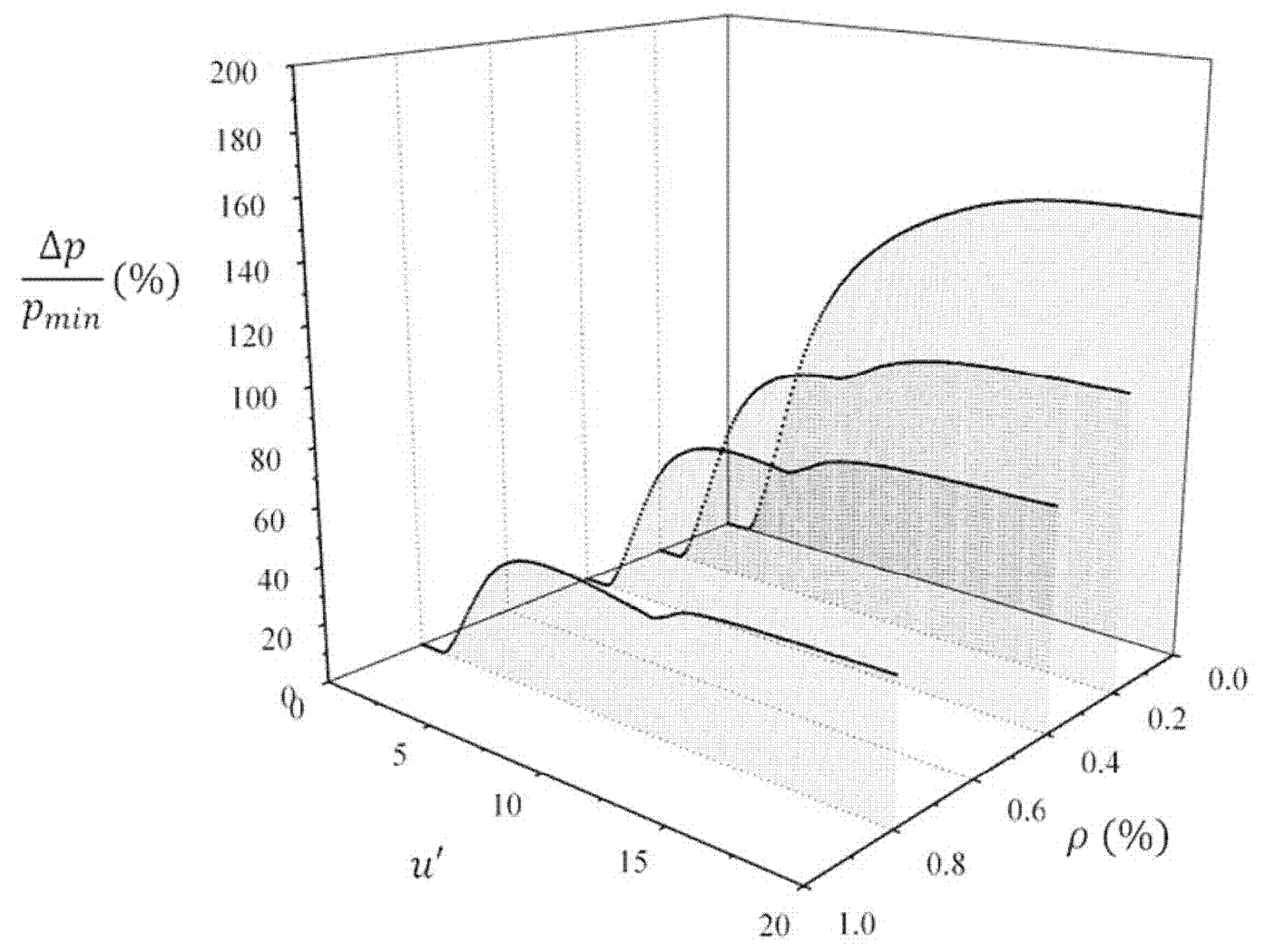

Fig. 11 - The effect of $\mu$ parameter of SH-FRC in terms of normalized increase of: (b) load carrying capacity $\left(\Delta p=p_{\mu=2.98}-p_{\min }, p_{\min }=p_{\mu=1.02}\right)$. 

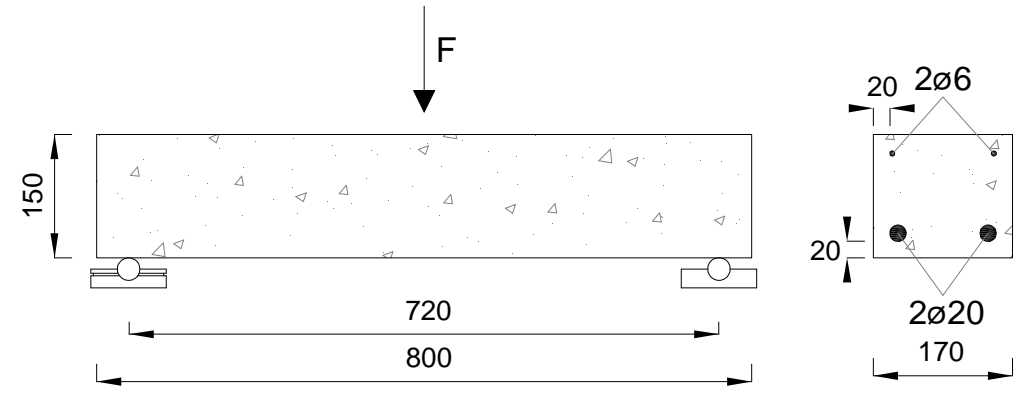

Fig. 12 - Ordinary reinforcement: a) transversal view; b) longitudinal view. 


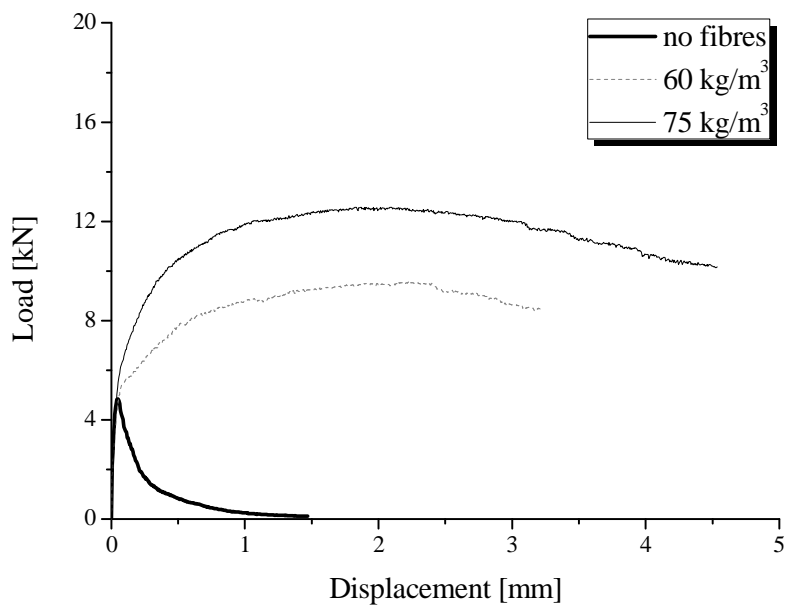

a)

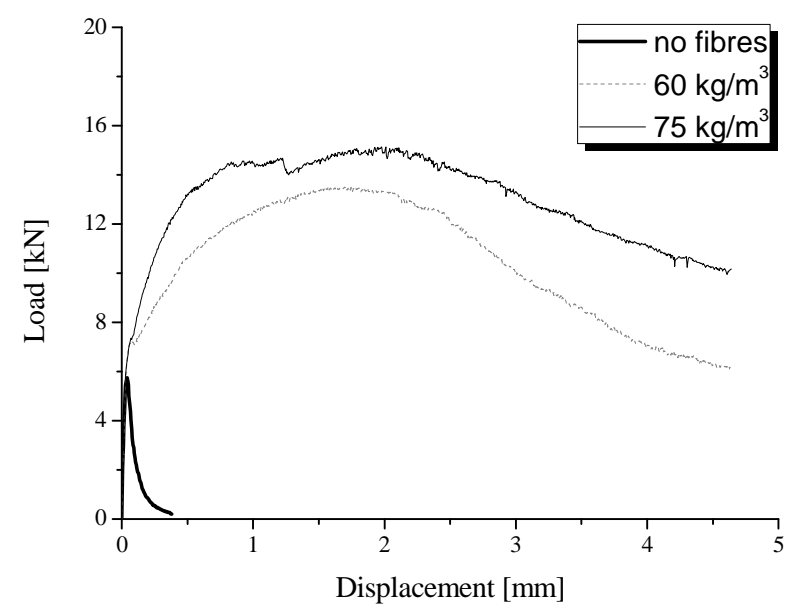

b)

Fig. 13 - Load-displacement curves of the bending tests with prismatic specimens of a) $f_{c m 50}$ and b) $f_{c m 70}$ series. 


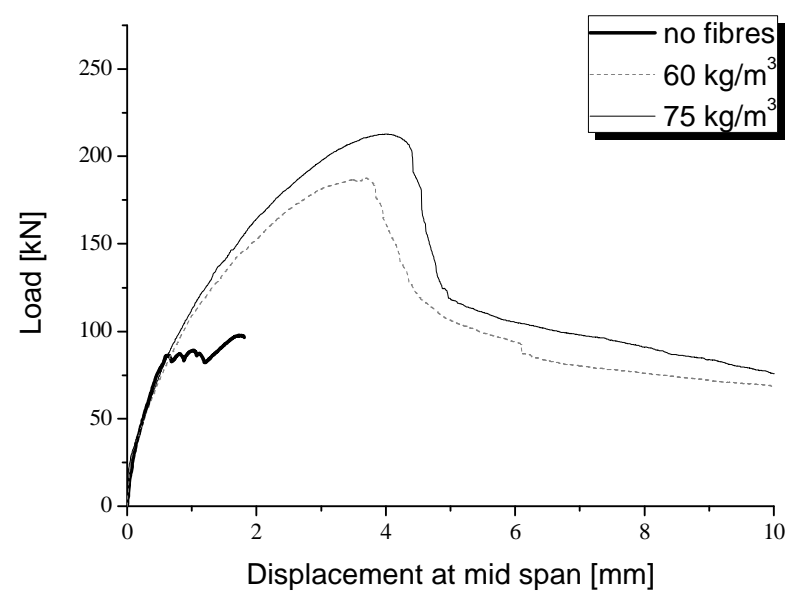

a)

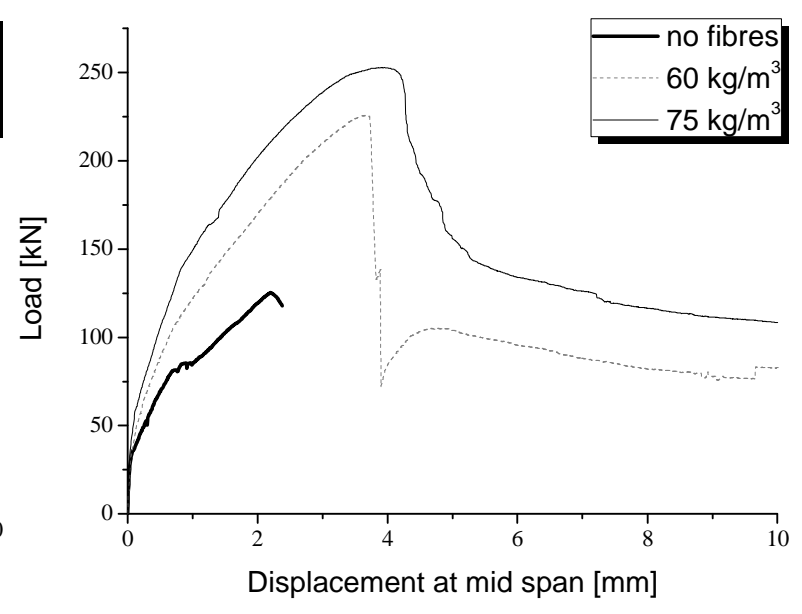

b)

Fig. 14 - Load-displacement curves for the a) $f_{c m 50}$ and b) $f_{c m 70}$ series. 


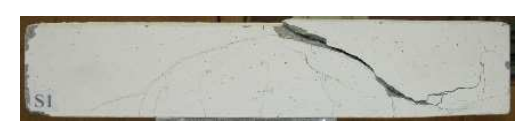

a)

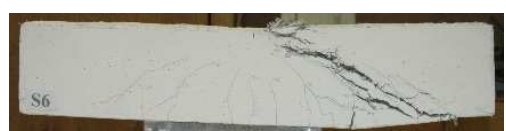

b)

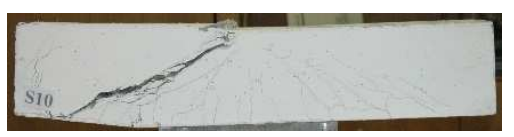

c)

Fig. 15 - Crack pattern in fcm50 series: a) without fibres, b) with $60 \mathrm{~kg} / \mathrm{m} 3$ and c) with $75 \mathrm{~kg} / \mathrm{m} 3$ of fibres. 


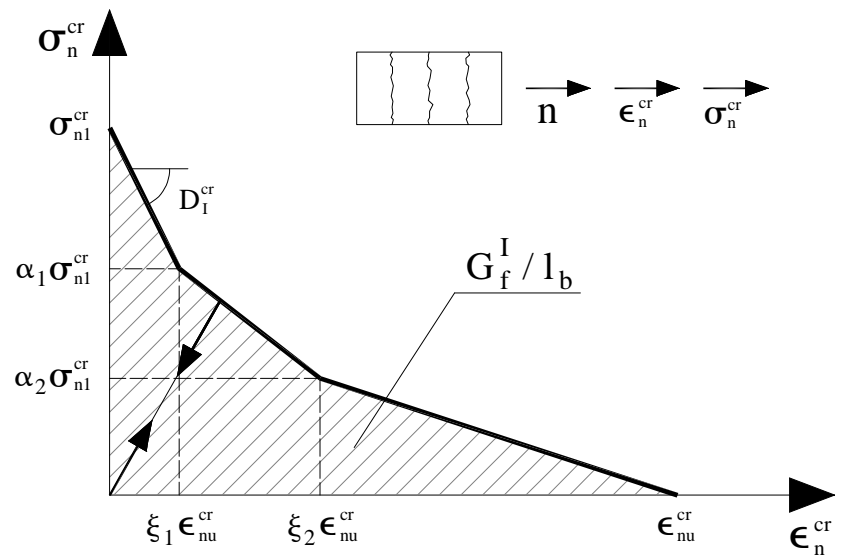

Fig. 16 - Tri-linear normal stress - normal strain diagram to simulate the fracture mode I crack propagation. 


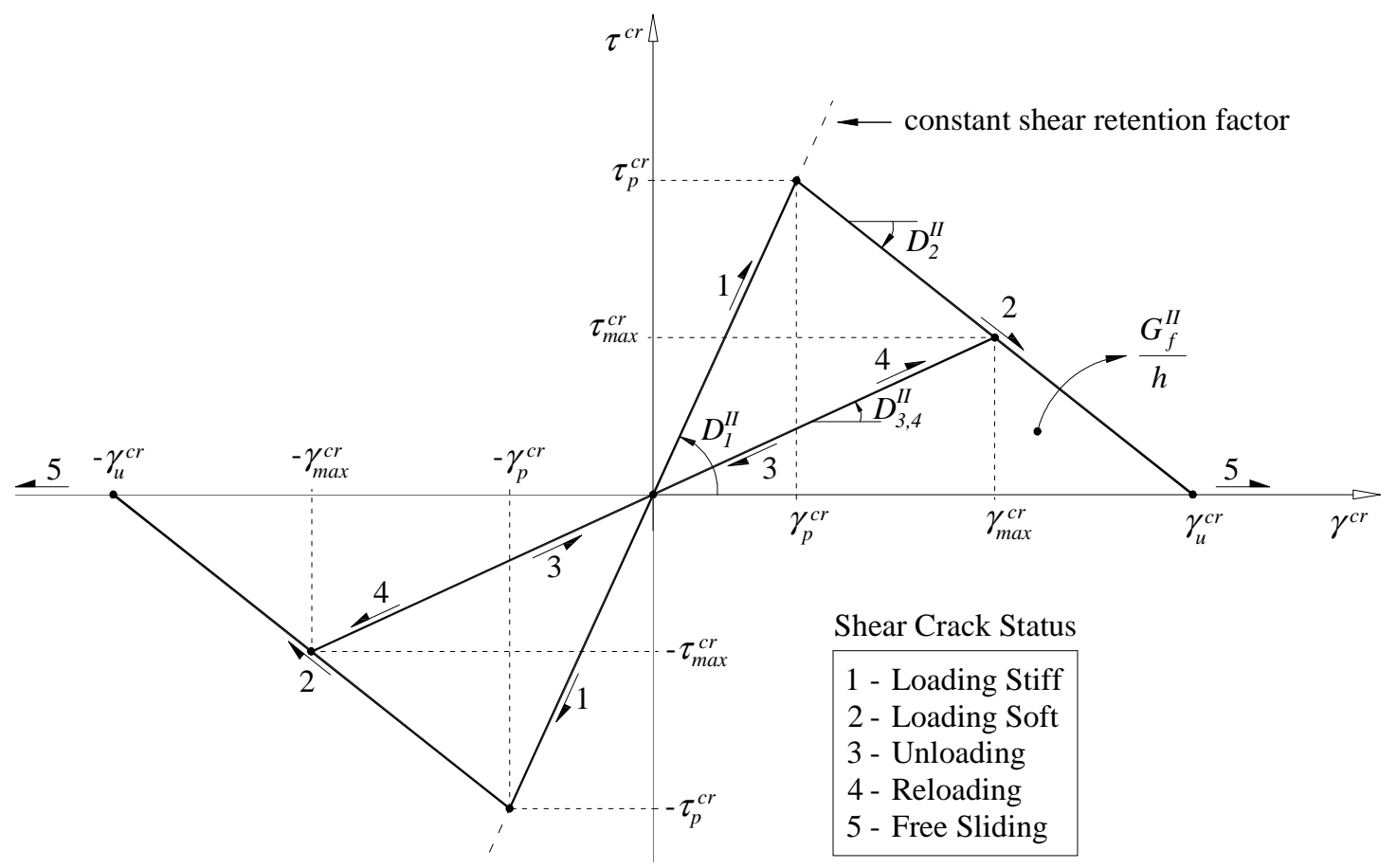

Fig. 17 - Bi-linear shear stress-shear strain diagram to simulate the fracture mode II crack sliding. 


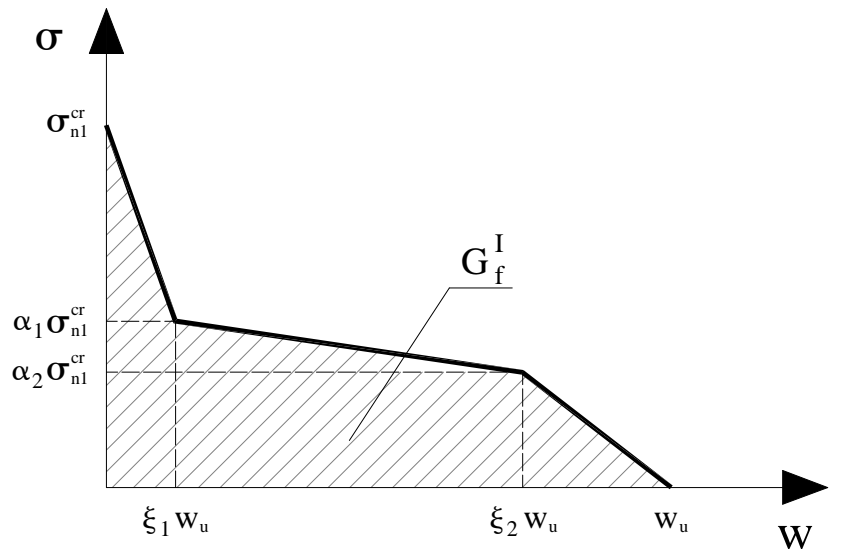

Fig. 18 - Stress-crack opening diagram. 
Interface

Elements

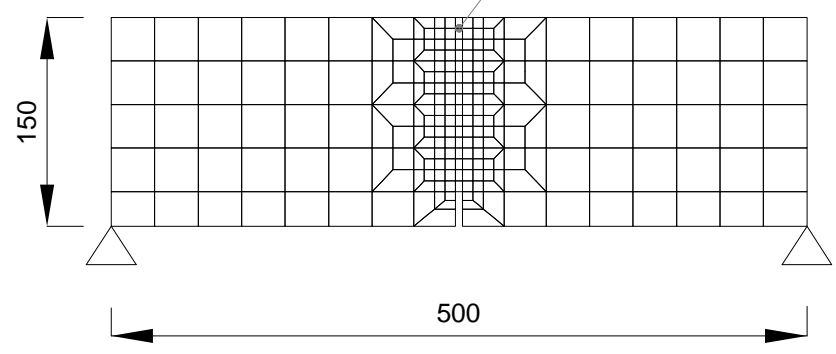

Fig. 19 - Finite element mesh adopted in the inverse analysis. 


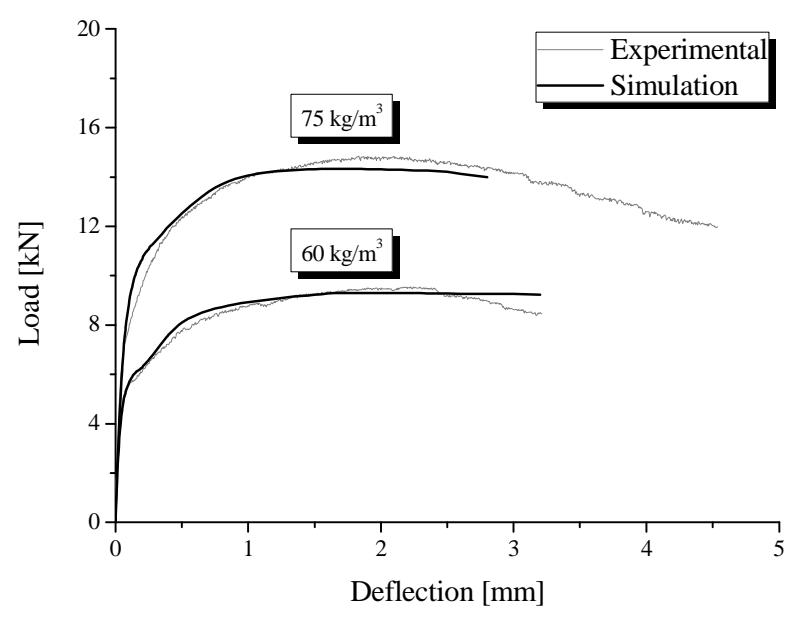

a) $f_{\mathrm{cm}}=50 \mathrm{MPa}$

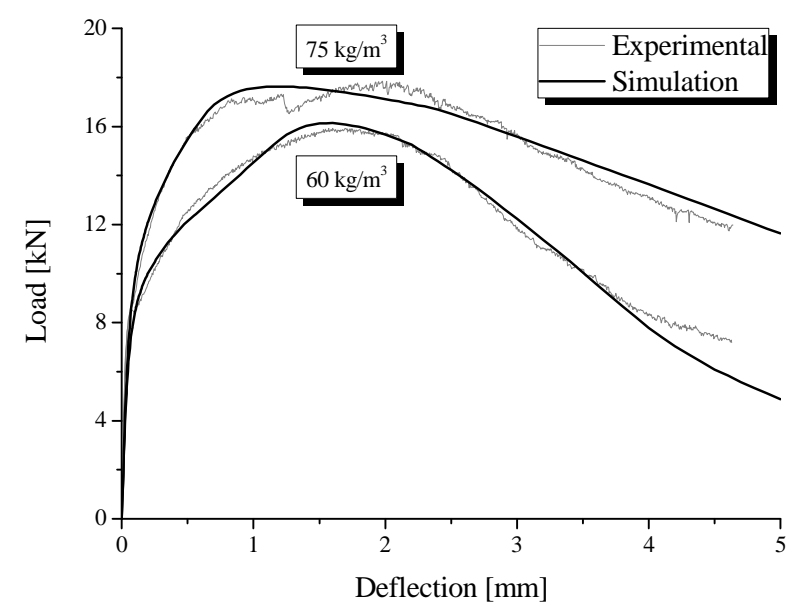

b) $f_{\mathrm{cm}}=70 \mathrm{MPa}$

Fig. 20 - Force-deflection curves of the notched beam bending tests: comparison between experimental and numerical results. 


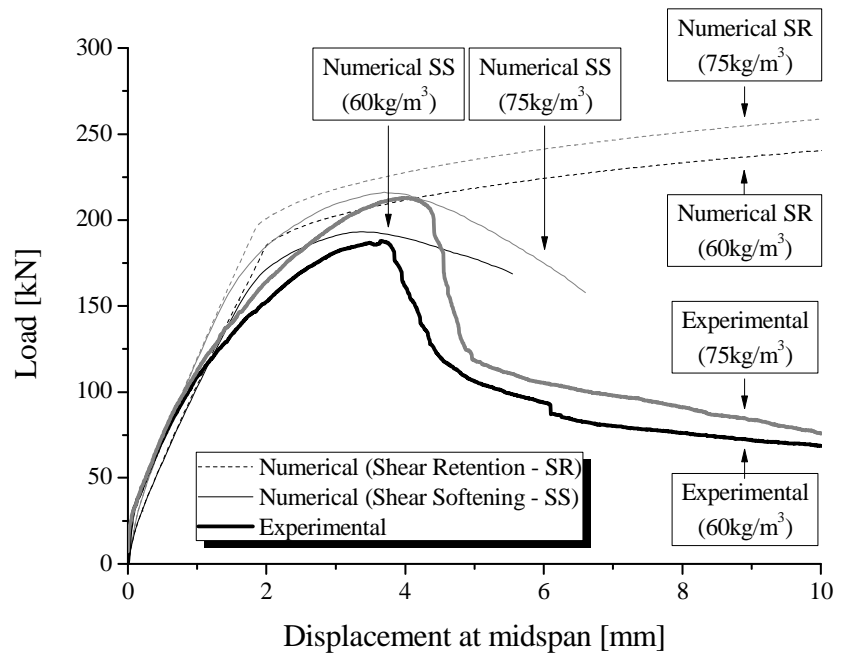

Fig. 21 - Relationship between the load and the midspan deflection for the distinct numerical simulations. of the RC beams ( $\left.f_{c m}=50 \mathrm{MPa}\right)$. 